\title{
RIVER SEDIMENT GEOCHEMISTRY AS A CONSERVATIVE MIXTURE OF SOURCE REgions: ObSERVATIONS AND PREDICTIONS FROM THE CAIRNGORMS, UK
}

ACCEPTED MANUSCRIPT, COMPILED NOVEMBER 29, 2020

\author{
Alex G. Lipp ${ }^{1 *}$, Gareth G. Roberts ${ }^{1}$, Alexander C. Whittaker ${ }^{1}$, Charles. J. B. Gowing ${ }^{2}$, and Victoria M. Fernandes ${ }^{1}$ \\ ${ }^{1}$ Department of Earth Sciences and Engineering, Imperial College London, UK \\ ${ }^{2}$ Centre for Environmental Geochemistry, British Geological Survey, Keyworth, UK
}

\begin{abstract}
The elemental composition of sediments in rivers is the product of physical and chemical erosion of rocks, which is then transported across drainage networks. A corollary is that fluvial sedimentary geochemistry can be used to understand geologic, climatic and geomorphic processes. Here we predict elemental compositions of river sediments using drainage networks extracted from digital elevation data and erosional models. The Geochemical Baseline Survey of the Environment was used to quantify substrate (i.e. source region) chemistry. Sedimentary compositions in rivers downstream are predicted by formally integrating eroding substrates with respect to distance downstream. Different erosional models, including the Stream Power model and uniform incision rates, are tested. Predictions are tested using a new suite of compositions obtained from fine grained $(<150 \mu \mathrm{m})$ sediments at 67 sites along the Spey, Dee, Don, Deveron and Tay rivers, Cairngorms, UK. Results show that sedimentary geochemistry can be predicted using simple models that include the topography of drainage networks and substrate compositions as input. The concentration of numerous elements including Magnesium, Rubidium, Uranium, Potassium, Calcium, Strontium and Beryllium can be accurately predicted using this simple approach. Predictions are insensitive to the choice of erosional model, which we suggest is a consequence of broadly homogeneous rates of erosion throughout the study area. Principal component analysis of the river geochemical data suggests that the composition of most Cairngorms river sediments can be explained by mafic/felsic provenance and conservative mixing downstream. These results suggest that the elemental composition of river sediments can be accurately predicted using simple erosional models and digital elevation data.
\end{abstract}

\section{Plain Language Summary}

The chemistry of sediments in rivers is used to understand many geologic, climatic and biotic processes including climate change and mountain building. For example, geochemical data acquired along rivers have been used to constrain rates of $\mathrm{CO}_{2}$ drawdown. Acquiring observations of river chemistry and testing their sensitivity to physical and chemical processes (e.g. tectonics, weathering, climate) is generally challenging. Therefore, developing methods to predict the composition of river sediments from first principles, or from readily available data, is attractive. We address this problem by combining maps of geochemical data with models of erosion to predict the composition of river sediments. These predictions are tested using new observations from the Spey, Dee, Don, Deveron and Tay rivers, which drain the Cairngorms mountains, UK. The model predictions capture the majority of the observed variation for most studied elements including Magnesium, Rubidium, Uranium, Potassium, Calcium, Strontium and Beryllium throughout drainage basins. Results suggest that the chemistry of river sediments are primarily mixtures of the composition of source regions. Physical erosion and the shape and connectivity of drainage basins controls the chemistry of river sediments downstream, other processes (e.g. storage) appear to play secondary, moderating, roles. In the Cairngorms, we find that most river sediment geochemistry can be related to mixing of just two types of rock (mafic and felsic).

\section{INTRODUCTION}

The elemental composition of river sediments is determined by the chemistry of the eroding substrate (e.g. bedrock, soils) and modified by processes including chemical weathering, cation exchange and hydrodynamic sorting (e.g. Bouchez et al. 2011, 2012; Lupker et al. 2016). Consequently, river sediment compositions are used to investigate controls on chemical and physical weathering rates (e.g. climate change, tectonics, geomorphic processes; Gaillardet et al. 1999; Riebe et al. 2003; Blanckenburg et al. 2012). Geochemical studies of fluvial sediment commonly make use of samples along rivers to qualitatively infer climatic or erosional processes upstream. In such studies, assumptions about how the upstream signal is integrated downstream are common, e.g. 'let nature do the averaging' (Blanckenburg 2005; Weltje 2012; Romans et al. 2016; Garzanti et al. 2018 and references therein). In this study we develop quantitative methodologies to objectively test such assumptions using geochemical data.

Predictive modelling of surface processes has become increasingly tractable due to the availability of high resolution topographic data and computationally efficient landscape evolution models (e.g. Braun et al. 2013; Hobley et al. 2017; Salles et al. 
2018; Salles 2019). These advancements have made it possible to make testable predictions about a range of observable characteristics such as exhumation rate and fluvial sedimentary flux (e.g. Fernandes et al. 2019). Extending such predictions to geochemical data is a reasonable next step.

The central aim of this study is to develop and test methodologies that can predict the elemental composition of river bedload sediments at any position in a drainage basin. Geostatistical approaches to interpolate geochemical data along stream networks have been proposed (e.g. Kim et al. 2017). Instead we take a deterministic modelling approach, which incorporates assumptions about how physical and chemical signals propagate through fluvial systems. Recently, landscape evolution models have been modified to make theoretical predictions about sediment provenance (e.g. Sharman et al. 2019). Predictions from such models could be tested using, for example, geochemical observations. Such predictions of sediment chemistry along drainage networks are desirable but require information about the chemistry in source regions. In this study, we therefore make use of high resolution regional geochemical surveys, generally produced for environmental monitoring and mineral exploration purposes (Garrett et al. 2008). These inventories can span large regions and contain samples acquired at regular intervals with a consistent methodology, which make them ideal for testing predictive models (Smith et al. 2013; Caritat et al. 2016).

We begin by describing how the geochemistry of sediment source regions can be constrained using stream-sediment geochemical data. We describe how sediment samples were gathered from higher-order rivers to test model predictions. Next we describe a methodology to predict higher-order bed material chemistry from topographic data and source region geochemistry. The fitness of this model and its input sensitivity is evaluated by comparing predictions to observations. Finally we discuss how this approach allows us to simplify the description of sediment sources in our studied region.

\section{Data AND Methods}

\subsection{Observed source region chemistry: G-BASE inventory}

To predict the composition of bed material in higher-order rivers we need to know the composition of material entering the drainage network. One way to constrain composition of source regions is by interpolating bedrock compositions. A drawback of this approach is that bedrock compositions might not have been affected by chemical weathering. As a result, predictions made using bedrock compositions probably overestimate the abundance of mobile elements. Moreover, sampling bedrock geochemistry at high resolution is challenging. A second way to define source region chemistry is to use the composition of soils. However, because top- and bottom-soil compositions are different, it is unclear which is representative of the material entering the drainage network. The ideal dataset for calibrating source region geochemistry would capture geochemical changes in the underlying bedrock as well as incorporate the effect of weathering. A dataset which fulfils both of these requirements are geochemical surveys of first-order stream sediments (i.e. streams with very small catchment areas). First-order stream sediments have already experienced weathering, unlike most bedrock, but are not internally heterogeneous like soils. First- order stream sediment geochemistry is also strongly controlled by the geochemistry of the underlying lithology. This strong relationship between bedrock and stream sediment geochemistry is widely documented (e.g. Kirkwood et al. 2016b; Everett et al. 2019).

We use the high resolution stream sediment Geochemical Baseline Survey of the Environment (G-BASE) to define substrate (i.e. source region) chemistry. G-BASE was produced by the British Geological Survey to map mineral resources and define environmental baselines. The survey acquired elemental chemistry of sediment samples acquired from low-order streams across the UK from the 1960s to 2014 (Johnson et al. 2005). The G-BASE survey is distinguished by its high spatial sampling density of 1 site per $\sim 2 \mathrm{~km}^{2}$. We note that other large scale base-line surveys exist, for example, the National Geochemical Survey of Australia, which samples at a density of 1 site per $5,500 \mathrm{~km}^{2}$ (Caritat et al. 2016). High-resolution geochemical surveys such as G-BASE are considered to primarily reflect changes in the geochemical composition of the underlying geology (Everett et al. 2019; Kirkwood et al. 2020).

The G-BASE survey sampled the fine $(<150 \mu \mathrm{m})$ fraction of bed material in low-order streams across the UK; sample density is $\sim 2 \mathrm{~km}^{2}$ in our study area. A broad suite of elements were measured from each sample. For the remainder of this study we focus on the following 22 elements, which were consistently recorded in the G-BASE inventory in the studied area: $\mathrm{Ba}, \mathrm{Be}$, $\mathrm{Ca}, \mathrm{Co}, \mathrm{Cr}, \mathrm{Cu}, \mathrm{Fe}, \mathrm{K}, \mathrm{La}, \mathrm{Li}, \mathrm{Mg}, \mathrm{Mn}, \mathrm{Ni}, \mathrm{Pb}, \mathrm{Rb}, \mathrm{Sr}, \mathrm{Ti}, \mathrm{U}$, $\mathrm{V}, \mathrm{Y}, \mathrm{Zn}$ and $\mathrm{Zr}$. For all studied elements apart from Uranium, Direct Reading Optical Emission Spectroscopy was used for the analysis. Delayed Neutron Activation was used to measure Uranium. Full details of the G-BASE sampling, analytical and quality control procedures are given by Johnson et al. (2018a,b). A description of the sampling procedure utilised by the G-BASE survey is given below. The G-BASE sample sites for our study area are shown in Figure 1c. The studied region was sampled by G-BASE between 1977 and 1980. It is unlikely that substrate geochemistry has changed dramatically since then for the following reasons. First, the primary control on stream-sediment geochemistry is the underlying lithology which we can regard as constant on the timescales we consider. Secondly, step changes in geochemical concentrations are not observed between surveys acquired years apart, which suggests continuity of spatial geochemical distributions (Everett et al. 2019). Finally, as far as we are aware, there has been no significant change in the drainage network (e.g. major hydroelectric installations) since the surveys were performed.

The concentration of most elements in the G-BASE dataset has a log-normal distribution. Therefore, to generate continuous maps of elements we interpolated the $\log _{10}$ transform of the $\mathrm{wt} \%$ of each element (where wt $\%=$ weight percent). The interpolated grids have a resolution of $200 \times 200 \mathrm{~m}$ (Figure 3e,f). The observations were interpolated using the continuous curvature splines methodology of Smith et al. (1990) with tension factor of 0.25 . Varying the tension factor between 0 and 1 made negligible difference to predictions.

\subsection{Study Region}

The Cairngorms region was chosen as it contains some of the highest topography in the UK. It also contains variable lithol- 

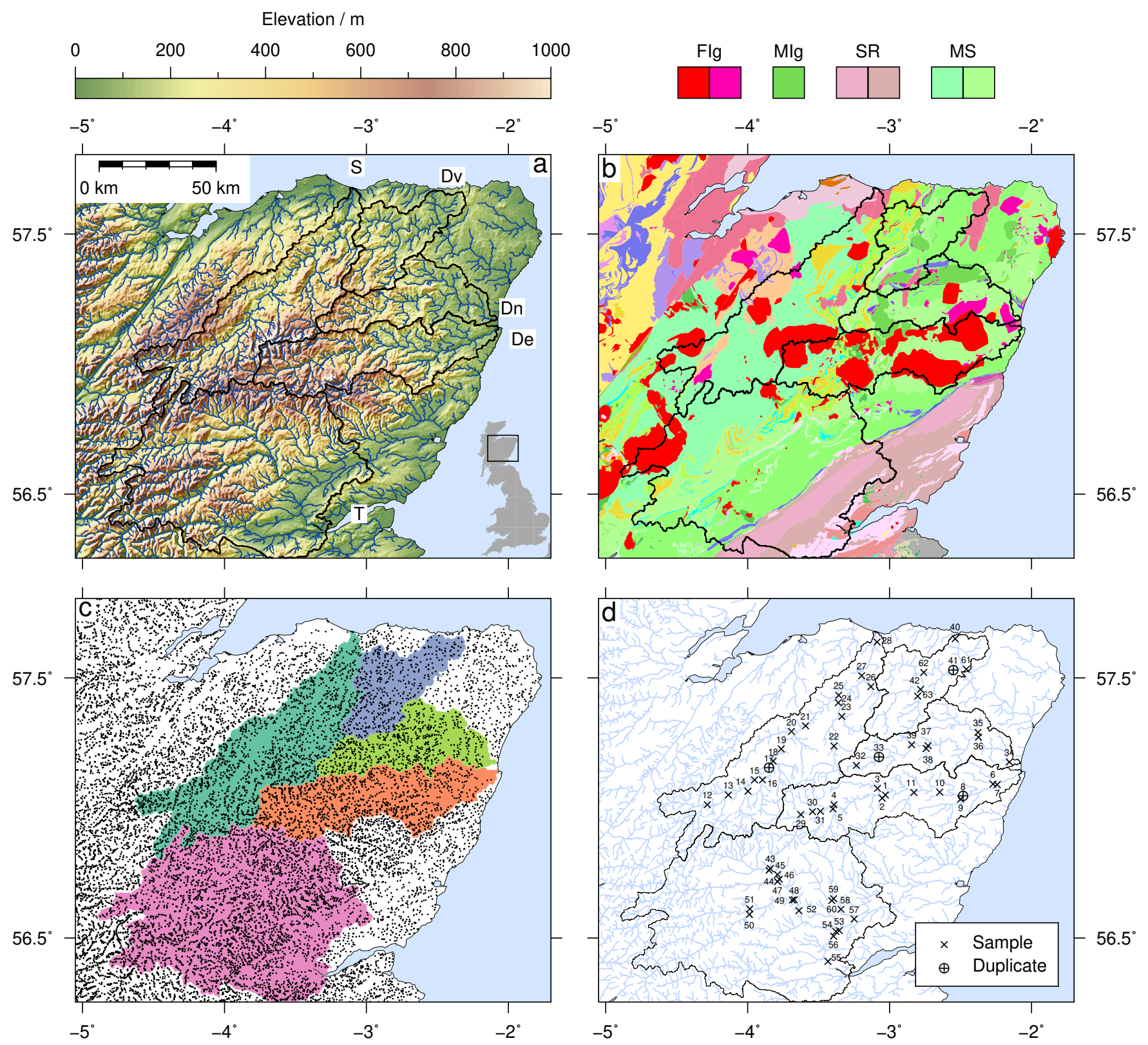

Figure 1: Introduction to studied region: Scotland, UK. (a) Topography from SRTM1s data set gridded to $200 \times 200 \mathrm{~m}$ squares. Blue $=$ rivers from CCM2 database (Jager et al. 2010). Rivers labelled: $\mathbf{S}=\mathrm{Spey}, \mathrm{Dv}=$ Deveron, $\mathrm{Dn}=\mathrm{Don}, \mathrm{De}=$ Dee, $T=$ Tay. Black lines indicate catchment boundaries. Inset map shows localition of study region within the rest of UK. (b) Geological map showing key lithologies: Flg = Ordovician to Devonian felsic igneous intrusions; Mlg = Ordovician to Silurian mafic igneous intrusions; $S R=$ Sedimentary rocks, mostly Devonian sandstones; $M S=$ Metasedimentary rocks, mostly Neoproterozoic psammites. See mapapps.bgs.ac.uk/geologyofbritain/home.html for full geologic key; reproduced with the permission of the British Geological Survey UKRI, all rights reserved. Black lines indicate catchment boundaries (c) Black circles $=$ G-BASE sample localities overlain on river catchments. (d) Sampled localities indicated by symbols. Numbers $=$ locality number. Black lines indicate catchment boundaries 
ogy (Figure 1b). For example, the Cairngorms massif contains Paleozoic felsic intrusions and mafic igneous rocks intruded into sedimentary and metasedimentary rocks. The diverse array of lithologies, combined with high natural sediment supply provides an opportunity to explore the roles that substrate geochemistry and erosional processes play in determining fluvial sediment geochemistry.

The region was covered by ice sheets during the last glaciation, which receded by $11.5 \mathrm{ka}$ resulting in a layer of till blanketing the region. Reworking of glacial deposits is a significant source of sediment in the region (Ballantyne 2008). The studied rivers all drain the glacially dissected granite plateau of the Cairngorms massif. The study area has a Warm Temperate/Humid climate $(\mathrm{CFb})$ in the Köppen climate classification (Kottek et al. 2006). A significant part of our studied region is contained within the protected Cairngorms National Park. Outside this region the dominant land-use is agricultural. There are no major urban areas upstream of any of the sample sites, although one sample was taken on the river Tay inside the city of Perth and another was acquired from the Don on the periphery of Aberdeen (Localities 55 and 34 in Figure 1d).

\subsection{Higher order river sediment sampling and analysis}

\subsubsection{Sampling}

The G-BASE dataset does not contain samples from higher order rivers and hence cannot be used to evaluate our model or investigate the length-scales at which downstream bed load geochemistry varies. Consequently, a new inventory of 67 samples was acquired for this study along higher-order rivers draining eastern Scotland, UK, in August 2019. We focus on the Spey, Tay, Dee, Don and Deveron rivers, which drain the Cairngorms massif and surrounding region of northeastern Scotland, UK (Figure 1).

Sample sites in the Spey, Tay, Dee, Don and Deveron catchments were chosen to include the main trunk from the upper reaches to the mouth and most major tributaries. Where possible, samples were gathered before and after a major confluence from both channels. The exact location of sample sites was determined by the practical need to access the river. To maintain consistency between the model input data and our test dataset, the sampling procedure was identical to the original G-BASE approach and used the same equipment (Figure 2a). The standard sampling procedure used for the G-BASE study, and repeated by this study, is described below.

We sampled the $<150 \mu \mathrm{m}$ fraction of bed-material. Bed material was extracted by shovel from the active channel of the river. Examples of sample sites are shown in Figure 2b-d. For practical reasons samples were gathered from bed material close to the bank, within $\sim 2 \mathrm{~m}$ (e.g. Figure 2c,d). If multiple shovel loads were required, as much as was possible, they were extracted from the same point in the channel bottom. The extracted sediment was first shaken through a $2 \mathrm{~cm}$ metal grill to remove pebbles. Subsequently, the wet sediment was deposited on a sieve stack on top of a fiberglass collecting pan. Using rubber gloves the sediment was rubbed through a $2 \mathrm{~mm}$ nylon mesh and washed through with a small amount of river water. This upper mesh was removed and the $<2 \mathrm{~mm}$ sediment fraction was then rubbed and washed through a $150 \mu \mathrm{m}$ nylon mesh into the collecting pan beneath. This procedure was repeated until $\sim 100 \mathrm{~g}$ of sediment had collected in the pan. The collecting pan was left undisturbed and covered for 20 minutes to allow sediment to fall out of suspension. Excess water, which contained some very fine sediment in suspension, was carefully decanted leaving a slurry of sediment behind. This slurry was homogenised and poured through a funnel into a labelled reinforced paper sample bag. Any sediment residue was then washed into the sample bag with a small amount of water. The bag was sealed and placed in a sealed plastic bag. A video showing the sampling procedure can be found in the Supporting Information.

To limit cross-contamination, the sampling kit was washed in river water, downstream of the site, before and after sampling. Sample numbers were pre-allocated in a randomised order. For example, localities 1, 2 and 3 had pre-allocated sample numbers CG020, CG062 and CG044 respectively. This randomisation was performed to avoid systematic bias during preparation and analysis, when samples were handled in numeric order (Johnson et al. 2018a). At the end of each field day samples were dried in the paper bags to remove excess water until they had the consistency of modelling clay. Special care was taken to avoid contaminating samples at this stage. The samples, still in the paper bags, were returned to their polythene bags and resealed. After the sample was concluded, samples were freeze-dried to remove any remaining moisture before short-term storage prior to analysis.

\subsubsection{Geochemical Analysis}

The freeze dried samples were disaggregated with a rubber mallet and homogenised by cone-quartering. $20 \mathrm{~g}$ of the homogenized sample were then powderised in an agate ball mill. Approximately $0.25 \mathrm{~g}$ of the milled powder was extracted and then accurately weighed in Savillex tubes for digestion. The samples were pre-digested in $\mathrm{HNO}_{3}$ to remove organic compounds. Subsequently the samples underwent hotplate mixed acid (HF, $\mathrm{HNO}_{3}$ and $\mathrm{HClO}_{4}$ ) digestion over a ramped heating procedure. After digestion the samples were resolubilised in aqueous $\mathrm{HNO}_{3}$ and $\mathrm{H}_{2} \mathrm{O}_{2}$. The liquid samples were then analysed for a full suite of elements by Inductively Coupled Plasma Mass Spectrometry. Comparison to external and internal standards indicates that, as expected for our method, some elements ( $\mathrm{Zr}, \mathrm{Y}, \mathrm{Ti})$ reported slightly lower concentrations in our standards than expected suggesting a small residue of particularly chemically resistant minerals such as Zircon. The majority of other elements in the standards were successfully reproduced. All sample preparation and analysis was carried out at the BGS Inorganic Geochemistry Facility in Keyworth, UK. The new data set of chemistry for higher-order rivers is provided.

\subsubsection{Nested duplicate and replicate analysis}

The goal of our study is to identify and predict geochemical differences between sample sites, i.e. intersite variability. These intersite differences may however be obfuscated if there is geochemical heterogeneity within each sample site, or introduced by our analytic procedure. To investigate the ability of our procedure to identify regional geochemical signals we conducted a nested sampling procedure (Figure 2e). Nested sampling procedures are commonly used in geochemical surveying to quantify the amount of intersite, intrasite and intrasample variability and 

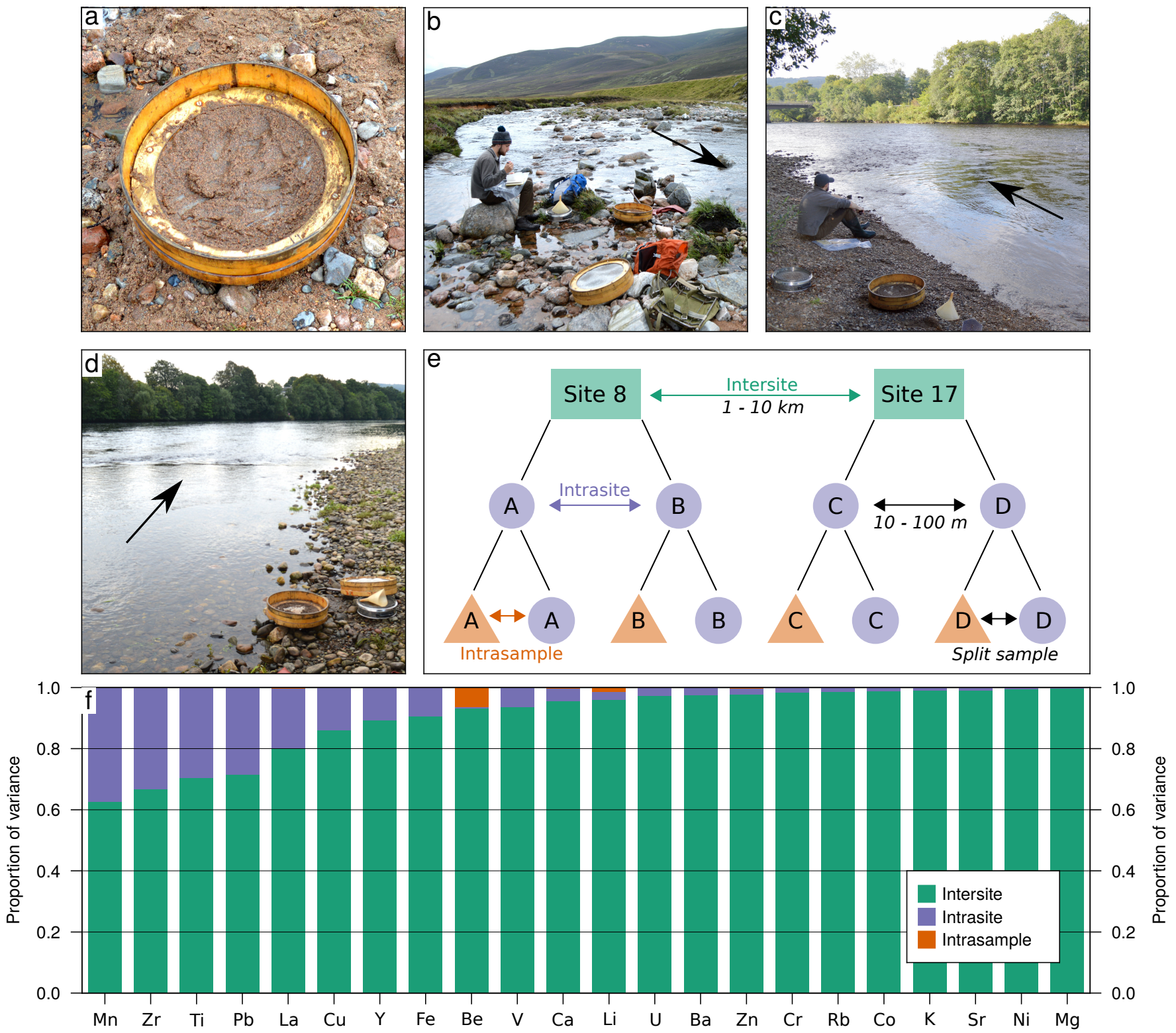

Figure 2: Sampling methodology and analysis of variance (ANOVA). (a) Nested sieve set used for sampling. Photograph shows sediment on top of $150 \mu \mathrm{m}$ mesh atop collecting pan; apparatus has a $45 \mathrm{~cm}$ diameter. (b) Photograph shows Locality 29 (upper reaches of River Dee); arrow indicates flow direction. (c) Locality 48, River Tummel, a tributary of Tay. (d) Locality 55, close to mouth of River Tay at Perth. (e) Schematic of nested sampling procedure. Coloured text under Site 8 indicates the hierarchy of variance (see panel f). Black text under Site 17 indicates how sample hierarchy was created. (f) Results of nested ANOVA indicates that most variance lies between sites for all studied elements, thus large scale geochemical signals dominate over local heterogeneity. Intrasample variance is negligible in most cases. 
hence evaluate the success of the sampling and analytical procedure.

We implemented this nested procedure by gathering duplicate samples at four randomly chosen localities (Figure 1d). The duplicate samples were gathered exactly as described above but at a distance of $\sim 100 \mathrm{~m}$ from the previous sampling point Prior to powderisation, each homogenised duplicate sample was then split into two 'replicate' samples to investigate intrasample variability such that each duplicated site yields four analyses (Figure 2e).

We use a nested Analysis of Variance (ANOVA) to quantify the intersite, intrasite and intrasample variance for each of the studied elements in the 16 replicate/duplicate samples (Garrett 1969). Nested ANOVA partitions an element's variance (the spread of values for a given element, given by $\sigma^{2}$ ) into specified hierarchies (e.g. Figure 2e). In doing so it reveals the contribution from intersite, intrasite and intrasample variability towards an element's variance. Because the elements had a log-normal distribution we perform ANOVA on each element after applying a $\log _{10}$ transform.

\subsection{Predicting sediment geochemistry}

\subsubsection{Elemental compositions}

The downstream composition of river sediment can be predicted using information about the properties of eroding substrate (e.g. elemental composition of substrate) and incision rates, $\partial z / \partial t$ In this study the former is quantified by the G-BASE dataset. A suite of observational and theoretical approaches exist to calculate incision rates and sedimentary fluxes at a range of spatial and temporal scales (e.g. Syvitski et al. 2007; Holbrook et al. 2014; Stephenson et al. 2014). For example, cosmogenic dating of fluvial terraces and erosion of radiometrically dated basalt flows constrain incision rates at spot locations on time scales of 1 kyr to 1 Myr (e.g. Karlstrom et al. 2008; Stucky de Quay et al. 2019). Erosional models are also frequently used to calculate incision rates continuously across a landscape.

First, for simplicity, we consider some spatially variable and measurable geochemical characteristic of sediment, $C$ (e.g. wt\% $\mathrm{MgO}$ ) in a single river. By assuming instantaneous transport of eroded sediment, the composition of river sediments $C_{\text {sed }}$ along a river of length $L$ is given by

$$
C_{\text {sed }}=\frac{1}{\int_{x}^{L} \frac{\partial z}{\partial t}(x) \mathrm{d} x} \int_{x}^{L} \frac{\partial z}{\partial t}(x) C(x) \mathrm{d} x .
$$

This expression calculates the contribution of source regions to the value of $C_{\text {sed }}$-by integrating the product of composition and incision rate with respect to distance downstream between positions $x$ and $L$. The contribution of elements from each eroding patch of the landscape are then normalised by total sedimentary flux.

It is straightforward to generalize this scheme to two (spatial) dimensions by integrating all of the upstream flowpaths from the point $x$. In this way, the composition of river sediments can be predicted using all of the eroding catchment upstream. To calculate a cumulative volumetric sedimentary flux, $Q_{\text {sed }}$, we integrate the incision rate across the entire upstream area, $A$, from a point, i.e.

$$
Q_{\text {sed }}=\int_{A} \frac{\partial z}{\partial t} \mathrm{~d} A .
$$

We make use of topographic data, $z(x, y)$, and continuous maps of source region geochemistry, $C(x, y)$, to parameterise these equations. This approach integrates all upstream regions that could contribute to compositions downstream. The twodimensional extension of Equation 1 is therefore:

$$
C_{\text {sed }}=\frac{1}{Q_{\text {sed }}} \int_{A} \frac{\partial z}{\partial t} C \mathrm{~d} A .
$$

For this study we choose to use erosional models to calculate incision rates due to our requirement for incision to be defined at all points in a landscape. Sparsely located point observations would be inappropriate for this purpose.

\subsubsection{Erosional models}

We first examine predictions from the widely used Stream Power erosional model, which relates incision rates to discharge and slope, $\partial z / \partial x$, through a power law relationship (e.g. Howard et al. 1983; Tucker et al. 2002). This model is simple, commonly used and can be readily extended to consider, for example, 'diffusive' geomorphic processes. Such diffusive processes can modify hillslope shapes in addition to the dominant fluvial 'advective' processes (e.g. Rosenbloom et al. 1994). Using upstream drainage area, $A(x)$, as a proxy for river discharge results in the following formulation of fluvial incision rate along a single river

$$
\frac{\partial z}{\partial t}=-v A(x)^{m}\left(\frac{\partial z}{\partial x}\right)^{n}
$$

where $v, m$, and $n$ are parameters that can be calibrated using the topology of drainage networks and independent geologic data (e.g. Stock et al. 1999; Quye-Sawyer et al. 2020). This formulation is often presented as $E(x, t)=-v A^{m} S^{n}$, where $S$ is slope and $E$ is erosion rate. The parameter $v$ is often interpreted as representing bedrock erodibility, which could vary as a function of lithology, structural weaknesses and climate (Howard et al. 1983; Whipple et al. 1999). The term $A(x)^{m}$ is a proxy for the power exerted on the river bed by the channel, where the value of $m$ is controlled by basin hydrology. Specifically, $m$ depends on both how channel width scales with discharge, and how discharge scales with upstream area. The parameter $n$ controls how the knickzone retreat rate depends on slope. For example, $n>1$ implies that steeper knickzones migrate faster than shallower ones for the same upstream area (Pritchard et al. 2009).

To calculate erosion rates across an entire two-dimensional landscape we solve a more general form of the Stream Power model, such that,

$$
\frac{\partial z}{\partial t}=-v A^{m}(\nabla z)^{n}
$$

where $\nabla z$ is the steepest cell-to-cell descent (see e.g. Salles et al. 2018). 

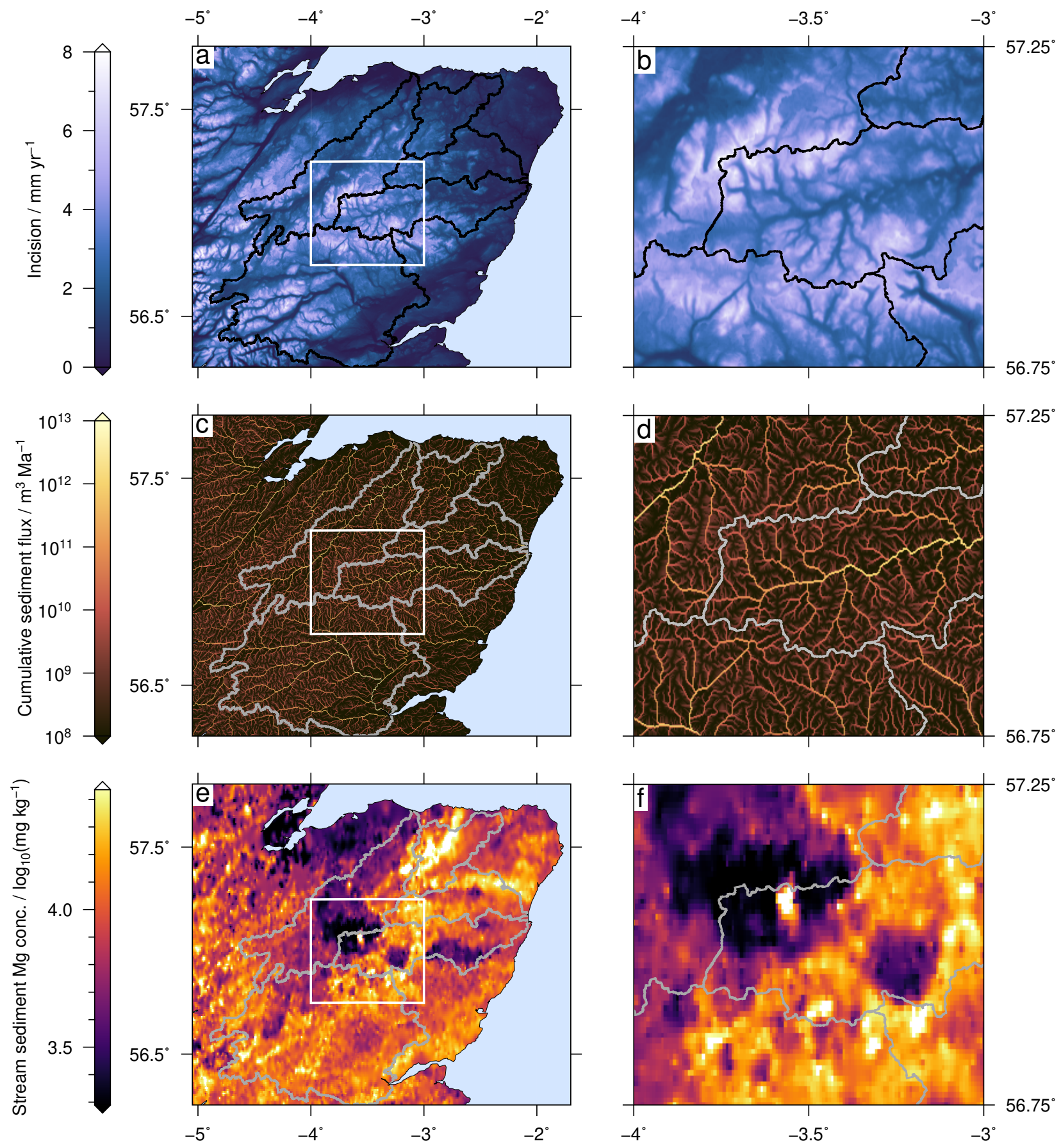

Figure 3: Inputs used in geochemical predictions. (a) Predicted incision, $\partial z / \partial t$, calculated using SRTM data set (Figure 1a) and Equation 3 with $n=1, m=0.35, v=3.62 \mathrm{~m}^{0.3} \mathrm{Ma}^{-1}$. Note that the $\mathrm{s}(\mathrm{b})$ White box = panel (b), which shows upper portion of Dee catchment. Grey lines indicate catchment boundaries. (c-d) Predicted cumulative sediment flux calculated by integrating incision (panel a) along flow paths. (e-f) Mg composition of first-order stream sediments interpolated from G-BASE localities using a continuous curvature spline with a tension factor of 0.25 (Figure 1c). Analogous maps were generated for all elements. 
Inverse modeling of large inventories of river profiles has shown that $n \simeq 1$ and $0.2 \leq m \leq 0.7$ produce theoretical river profiles that best fit observed longitudinal river profiles in Eurasia, North and South America, Africa and Australia (e.g. Paul et al. 2014; Rudge et al. 2015; Fernandes et al. 2019). Therefore, we start by assuming spatially constant values of $n=1$ and $m=0.35$ (Figure $3 \mathrm{a}-\mathrm{d}$ ). We start by assuming that $v$ is also constant; as such the predicted composition of sediment is independent of its specific value. However, as an intermediate step in our calculations $v$ must be specified so we, arbitrarily, use a value of 3.62 $\mathrm{m}^{1-2 m} \mathrm{Myr}^{-1}$ following Paul et al. (2014). We acknowledge that a range of different values of $m$ and $n$ are preferred (see Whipple et al. 2002; Royden et al. 2013 and references therein). As a result we explore the sensitivity of our model by systematically varying erosional parameter values (e.g. $n=2, m=0.35$ $n=1, m=0.6)$. We also consider a simple scenario in which incision rates are constant across the landscape. The appropriateness of chosen parameters is assessed by calculating misfit between observed and predicted chemical compositions along higher-order rivers.

\subsubsection{Implementation}

Equations 3 and 5 are implemented using the LandLab package in python 3 (Van Rossum et al. 2009; Hobley et al. 2017). The SRTM1s topographic dataset was gridded to $200 \times 200 \mathrm{~m}$ squares following a cylindrical equal-area projection centred on our study area using GMT 5.4 .5 (Farr et al. 2007; Wessel et al. 2013). Performing the calculations with a finer resolution grid significantly increases computation time. Depressions in the topography were filled using the 'priority-flood' algorithm and flow directions are computed using the 'D8' algorithm (see Barnes et al. 2014). Code to reproduce our implementations of Equations 3 and 5 are provided (see Acknowledgements for access details).

\section{Results}

\section{$3.1 \quad$ Nested ANOVA}

The results of the nested ANOVA showing the proportion of variance in each hierarchy is shown in Figure $2 \mathrm{f}$. The intersite variance accounts for $>90 \%$ the total variability for most elements. This result indicates that regional geochemical signals dominate over local variability. In most instances, the intrasample variance, which mostly reflects measurement uncertainty in our analytical procedure, is negligible. For Be, the relatively high intrasample variance is also reflected in the digestion repeats where Be shows variability between the repeats. Given that the intrasample variability is so small for all elements we use the arithmetic mean of the two replicates to represent the duplicate value for subsequent analyses. We conclude that our sampling and analytical methodology is successful in identifying regional geochemical signals between sample sites.

\subsection{Evaluating Predictions}

Figure $4 \mathrm{a}$ shows observed sediment $\mathrm{Mg}$ concentrations and model predictions. Figures 5 show results for elements that are well matched by predictions. Figures 6 and 7 show results, alphabetically, for other elements predicted by our model. Figure 8 shows results for elements poorly matched by the model.
The model predictions show variability in sediment geochemistry, even across relatively small areas. For example, the Don has a higher predicted $\mathrm{Mg}$ concentration at its mouth than the Dee, despite being separated by only $\sim 4 \mathrm{~km}$ (Figure 4 ). River chemistry is predicted to evolve along river channels. The Dee, for example, has very low predicted concentrations of $\mathrm{Mg}$ in its upper reaches but sediment becomes progressively more enriched in $\mathrm{Mg}$ towards its mouth. Variability on this scale can be observed in the predictions for all elements. This variability is validated by the nested ANOVA results which indicate that the primary geochemical signal in bed material exists between different rivers and topologically distinct points within a drainage network. Visual inspection of maps showing observed and theoretical sediment chemistry indicates that our simple model, which incorporates substrate chemistry and drainage networks, can reliably predict river sediment chemistry for many elements.

We formally compare the observed and predicted elemental concentrations by calculating Root Mean Square (RMS) misfit and $R^{2}$ values. These statistics are calculated using the $\log _{10}$ transformed data for two reasons. First, the data has a log-normal distribution, and secondly, if raw data (wt\%) was used, strong heteroscedasticity was observed, which violates the underlying assumptions of the chosen statistics. If the log-transform was not used, undue weight was applied by the regression algorithm to samples with high concentrations skewing the results. To extract model predictions for each observation we select the closest model cell that exists in a channel (defined as a cell with upstream area $>25 \mathrm{~km}^{2}$ ). This procedure was checked manually for each locality. These statistics are given for every element alongside the results maps (Figures $4-8$ ).

The misfit is calculated as the difference between the (log transformed) predicted and observed values, i.e. $\log _{10} C_{o}-\log _{10} C_{c}$. In most instances the misfits of the elements are distributed around 0 indicating limited bias. $\mathrm{Ca}$ is the only element which is systematically underpredicted by our model, despite having a high $R^{2}$ value (Figure $5 \mathrm{~d}$ ). 8 of the studied elements (K, Mn, $\mathrm{U}, \mathrm{Zr}, \mathrm{Li}, \mathrm{Co}, \mathrm{Ti}, \mathrm{Y}$ ) are overestimated by our model. This overprediction can be partially explained by our analytical procedure which can leave strongly resistate minerals only partially digested. Zr, Y and Ti are often hosted in resistate minerals such as Zirconium and Titanite and hence could be more abundant in the higher-order river samples than our results indicate. Even in these instances of over/under-prediction the fitted regression lines are parallel or sub-parallel to the target 1:1 line. Exceptions to this are $\mathrm{Pb}, \mathrm{Mn}$ and $\mathrm{Y}$. Plotting the misfits spatially shows no spatial bias, such as shown for Mg in Figure 4b. Maps of misfit for all elements can be found in the Supporting Information.

The RMS and $R^{2}$ values for every element are displayed graphically in Figure 9a. For multiple elements such as V, Rb, U and $\mathrm{K}$ (in total 9 out of 22 , or $41 \%$ ), the predictions account for $>70 \%$ of the observed variability (Figure 5 ). For the majority of elements, (in total 15 out of 22 , or $68 \%$ ) the $R^{2}$ value is $>0.5$, which indicates that the model successfully captures the majority of the observed variability.

\subsection{Model sensitivity}

We quantified the extent to which our model predictions are sensitive to different erosional parameters by changing the values in the model and observing resultant model predictions. We find 


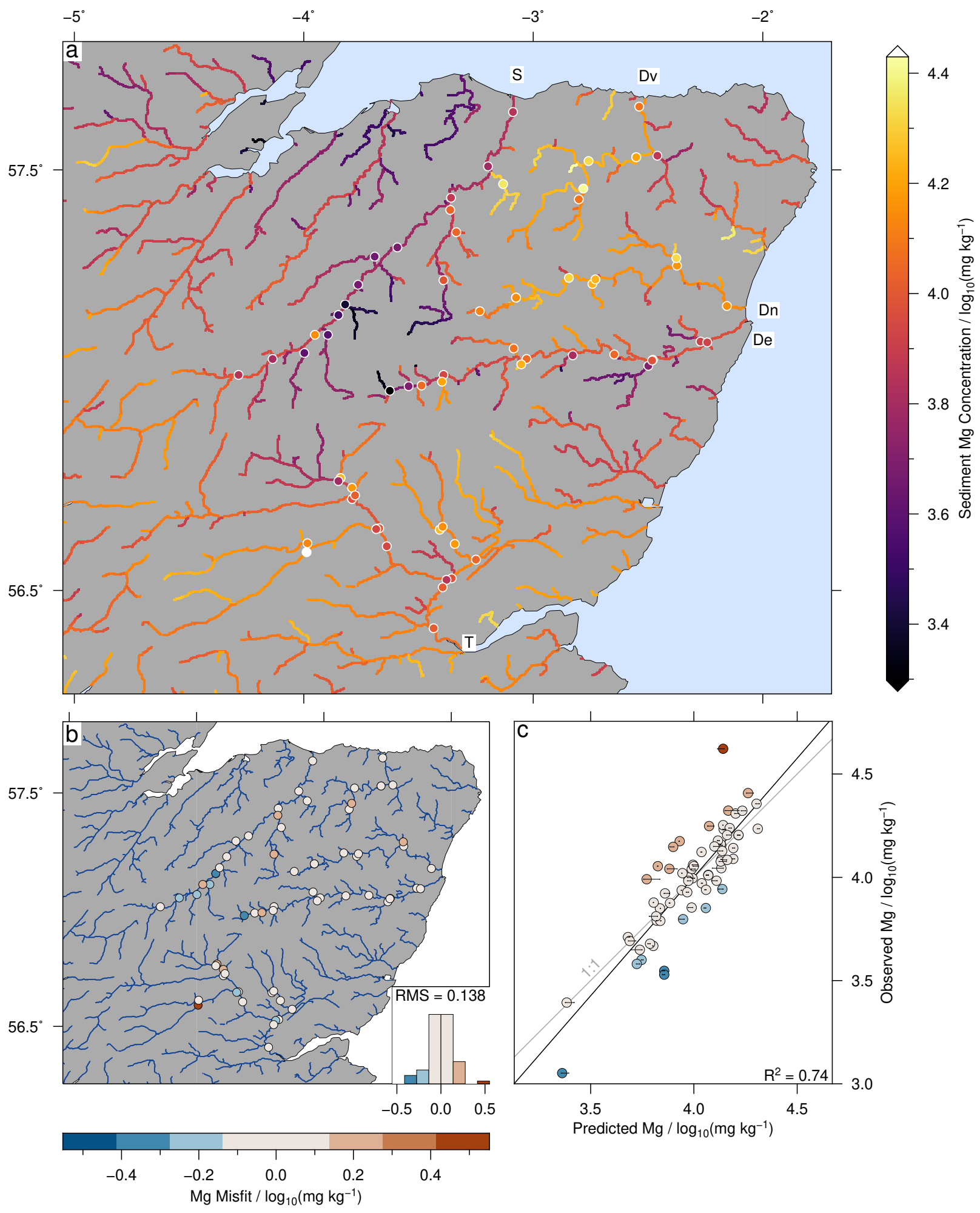

Figure 4: Comparison of model predictions and observations for $\mathrm{Mg}$. (a) Coloured circles $=$ observations of sediment $\mathrm{Mg}$ concentrations; continuous coloured lines = predicted sediment Mg concentration; note that colours have logarithmic scale. Rivers labelled: $\mathrm{S}=$ Spey, $\mathrm{Dv}=$ Deveron, $\mathrm{Dn}=$ Don, $\mathrm{De}=$ Dee, $\mathrm{T}=$ Tay. (b) Misfit between observations and predictions at sample sites $\left(\log _{10} C_{o}-\log _{10} C_{c}\right)$; negative (blue) and positive (red) values indicate over- or under-prediction, respectively. Inset histogram shows misfit; bin width is equal to root-mean-square misfit (RMS). (c) Cross plot of observations and predictions. Grey line shows 1:1 relationship. Black line shows linear regression through points, $R^{2}=0.74$. Lines adjacent to points show range of predictions generated by $0.05 \leq n \leq 1.95$ (see Equation 4). 

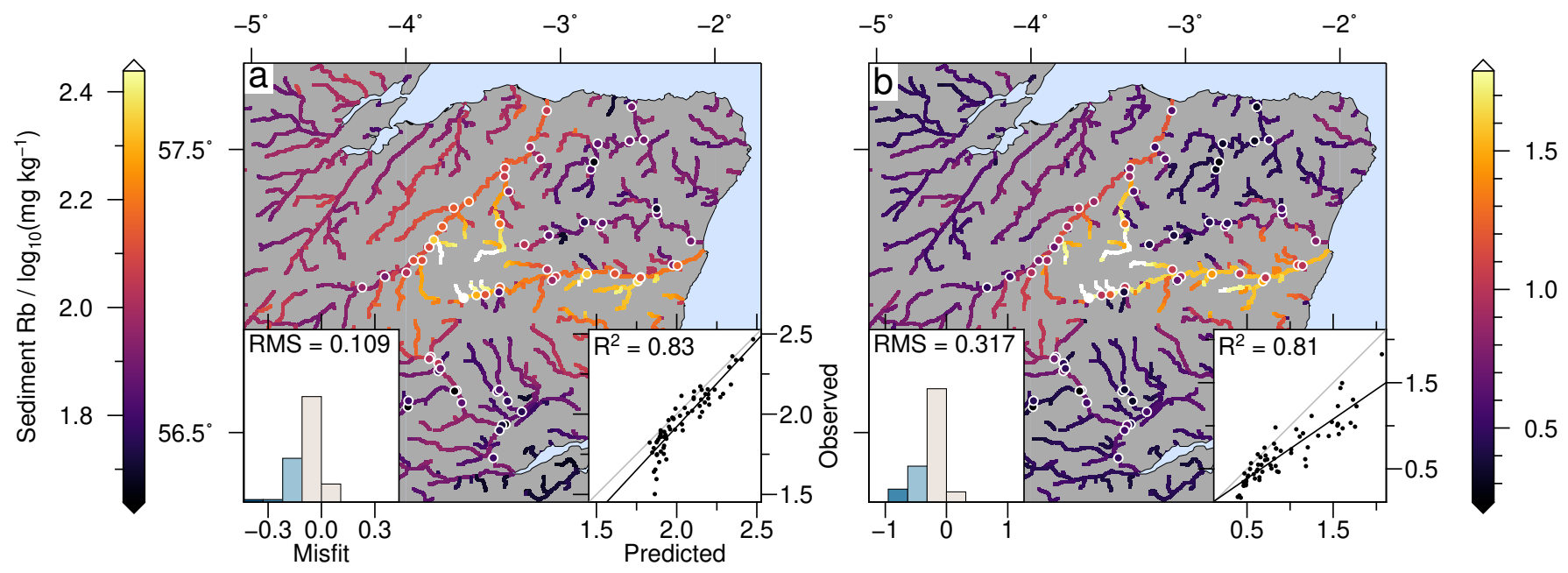

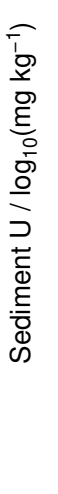
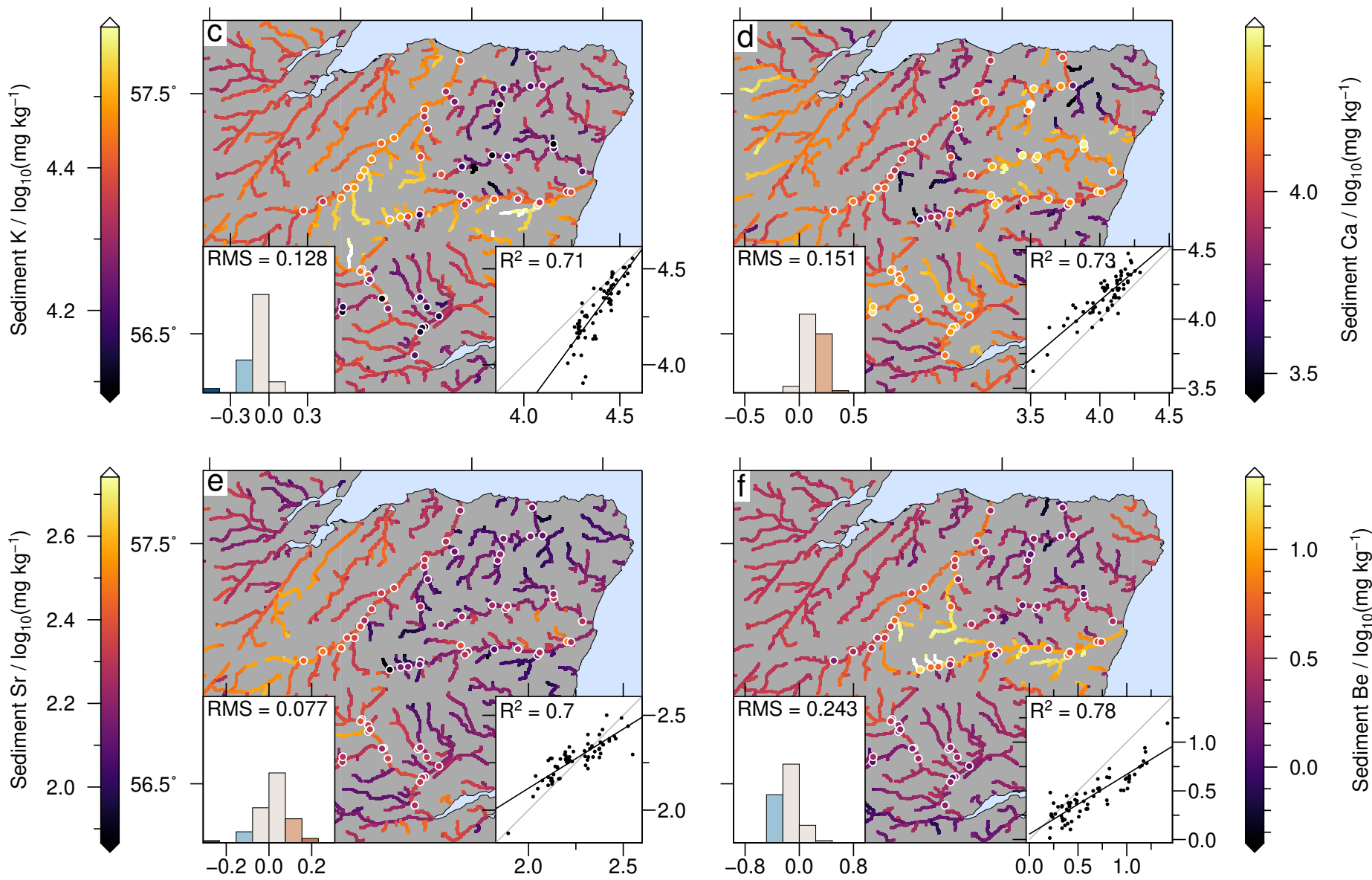

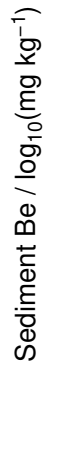

Figure 5: Comparison of observations and most accurate predictions. (a) Observed Rubidium concentrations (coloured circles) overlain on model predictions (coloured curves). Note logarithmic colour scale. Right inset shows cross plot of observations and predictions; grey line is 1:1 relationship; black line is linear fit to points; annotation shows $R^{2}$ value. Left inset is histogram of misfits; bin width is equal to RMS misfit; blue/red indicate over-/under-prediction. (b) Uranium. (c) Potassium. (d) Calcium. (e) Strontium. (f) Beryllium. Results for elements with less accurate predictions are shown in Figure 8. Results for all other elements are shown in Figures 4, 6 and 7. 

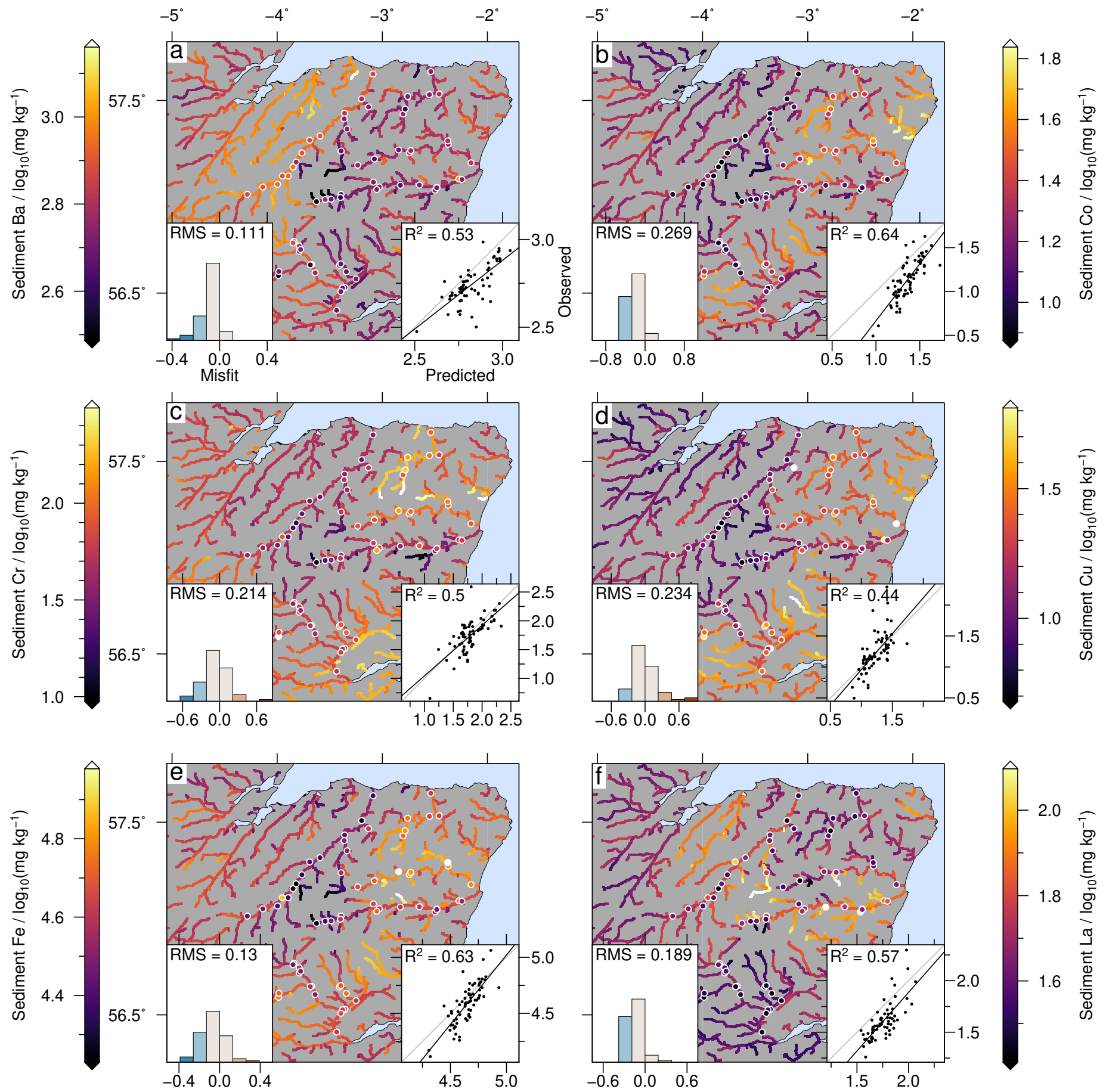

Figure 6: Comparison of observations and predictions for elements modelled by our approach. (a) Observed Barium concentrations (coloured circles) overlain on predictions (coloured curves). Note logarithmic colour scale. Right inset shows cross plot of observations and predictions; grey line is 1:1 relationship; black line is linear fit to points; annotation shows $R^{2}$ value. Left inset shows histogram of misfit between observations and predictions; bin width is equal to RMS misfit; blue/red indicate over-/under-prediction. (b) Cobalt. (c) Chromium. (d) Copper. (e) Iron. (f) Lanthanum. Results for all other elements are shown in Figures 4, 5,7 and 8 

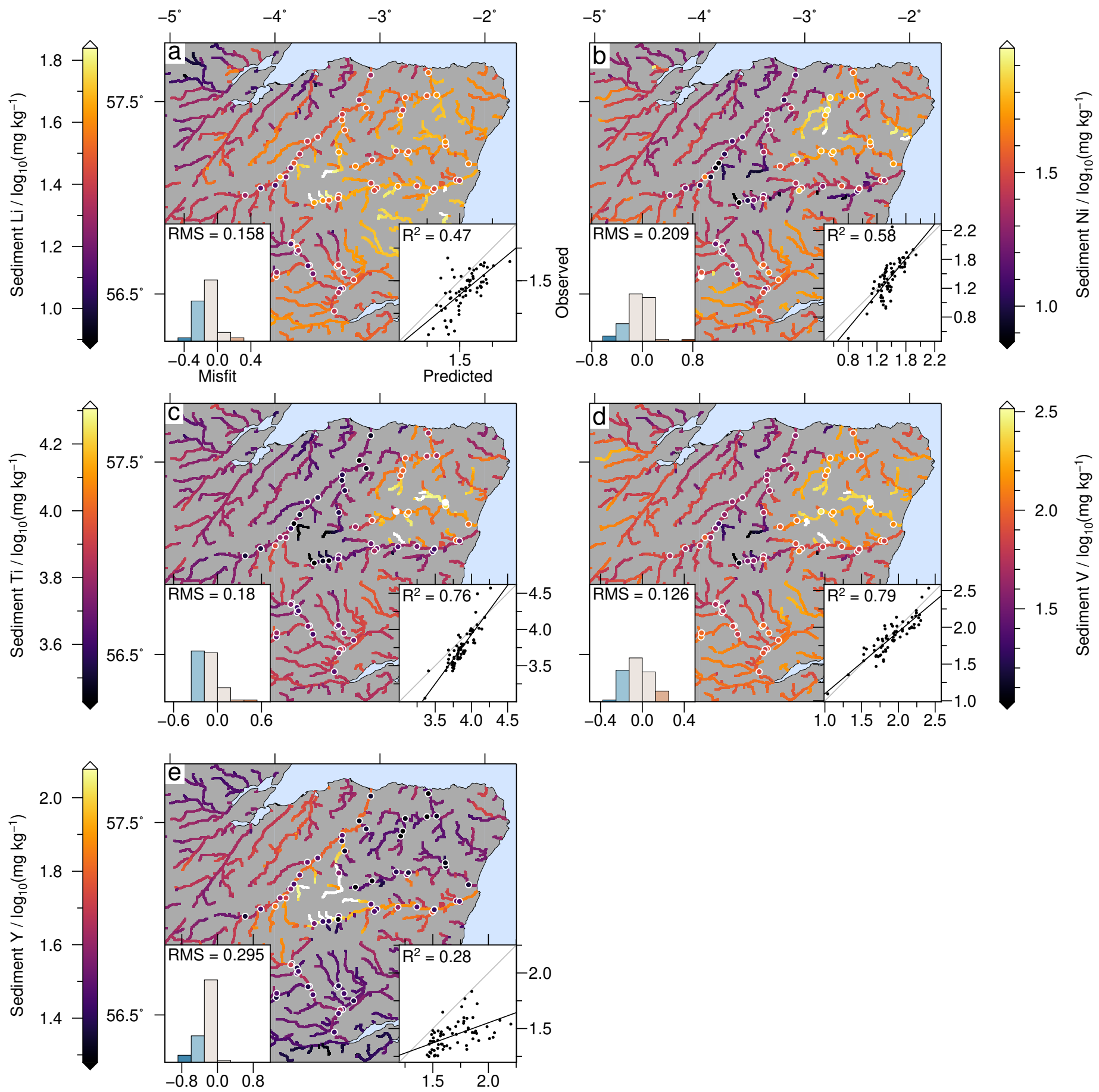

Figure 7: Comparison of observations and predictions for elements modelled by our approach. (a) Observed Lithium concentrations (coloured circles) overlain on predictions (coloured curves). Note logarithmic colour scale. Right inset shows cross plot of observations and predictions; grey line is 1:1 relationship; black line is linear fit to points; annotation shows $R^{2}$ value. Left inset shows histogram of misfit between observations and predictions; bin width is equal to RMS misfit; blue/red indicate over-/under-prediction. (b) Nickel. (c) Titanium. (d) Vanadium. (e) Yttrium. Results for other elements modelled by our approach. Results for all other elements are shown in Figures 4, 5, 6 and 8. 

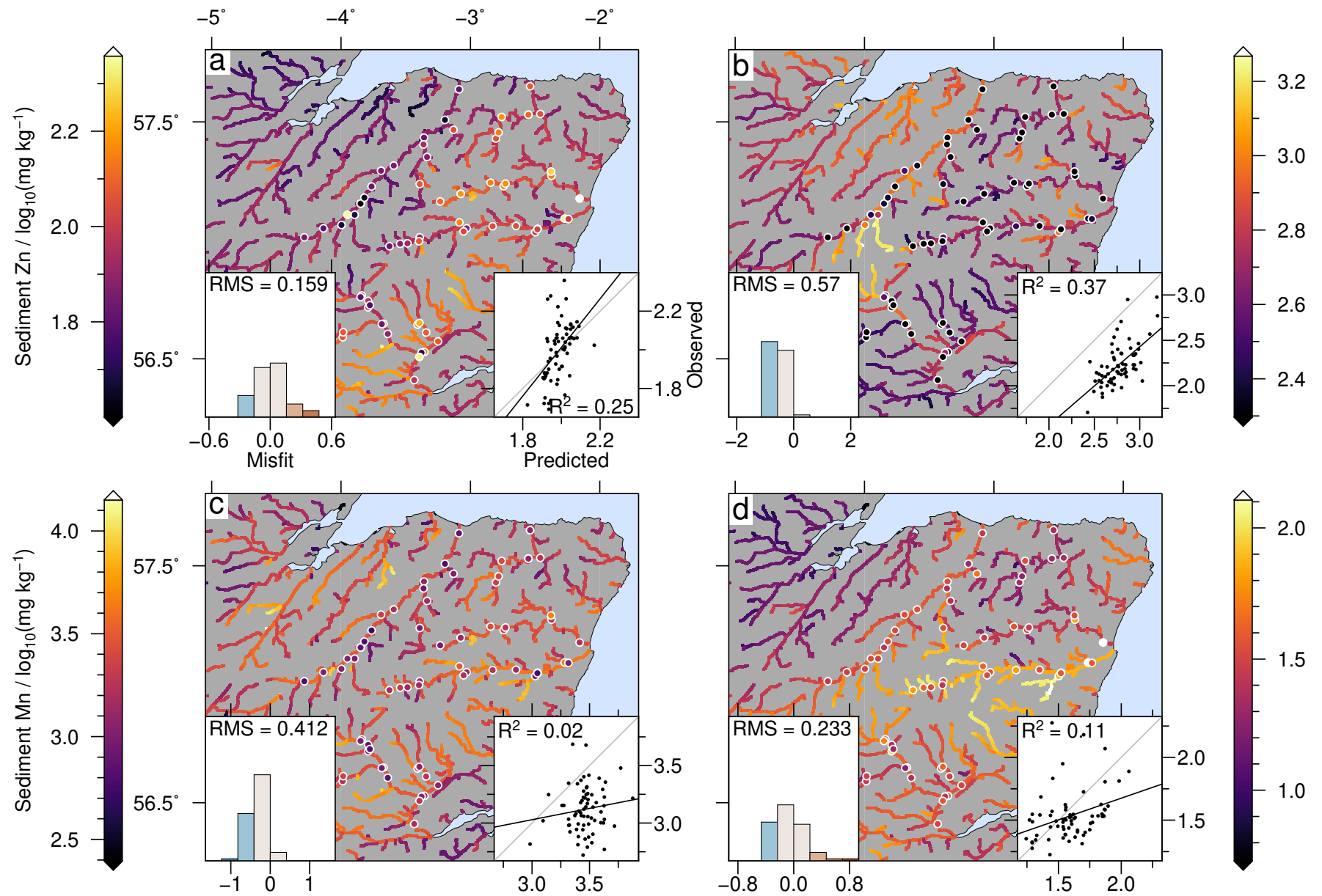

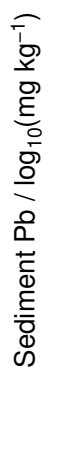

Figure 8: Comparison of observations and least accurate predictions. (a) Observed Zinc concentrations (coloured circles) overlain on predictions (coloured curves). Note logarithmic colour scale. Right inset shows cross plot of observations and predictions; grey line is 1:1 relationship; black line is linear fit to points; annotation shows $R^{2}$ value. Left inset shows histogram of misfit between observations and predictions; bin width is equal to RMS misfit; blue/red indicate over-/under-prediction. (b) Zirconium. (c) Manganese. (d) Lead. Results for elements with more accurately predicted concentrations are shown in Figure 5. Results for all other elements are shown in Figures 4, 6 and 7. 
that our model is insensitive to different erosional parameter values. Changing the value of the exponent $n$ (but keeping all other parameters the same) between $0.05-2$ in Equation 4 has a very limited effect on the predicted geochemistry and only very weakly affects the model fit where the maximum change in $R^{2}$, for $\mathrm{Ca}$, is from 0.73 to 0.70 (Figure $4 \mathrm{c}$; Figure $9 \mathrm{~b}, \mathrm{c}$ ). Similarly, using a different $m$ value of 0.6 also had a small effect on model fit, where the maximum change of $R^{2}$ was for $\mathrm{Sr}$ from 0.70 to 0.69 (Figure $9 \mathrm{~b}, \mathrm{c}$ ). Assuming a completely homogeneous incision rate across the studied area resulted in a small increase in $R^{2}$ value for 17 out of 22 of our studied elements (Figure $9 \mathrm{~b}, \mathrm{c})$. The maximum increase in $R^{2}$ was observed for $\mathrm{Ba}$ from 0.53 to 0.57 .

By contrast, our model is very sensitive to the geochemical input. We explored this sensitivity first by spatially randomising the original G-BASE input prior to interpolation and secondly by using an equally sized rectangle of G-BASE data from an arbitrarily chosen part of the UK (Wales). These alternative inputs are shown, for the case of $\mathrm{Mg}$, in Figure S1 of the Supporting Information. Using these different geochemical inputs results in much lower $R^{2}$ values for all elements with all $R^{2}$ values dropping to below 0.2 and an appreciably higher RMS misfit in all instances. Consequently, the success of our model when using the 'true' G-BASE dataset is not simply coincidental and reflects a successful integration of the upstream geochemistry. This result emphasises that input geochemistry must be known in some detail to predict downstream geochemistry.

\section{Discussion}

\subsection{Explaining successful prediction of sediment geochemistry}

The results of the ANOVA indicate that regional (kilometer to tens of kilometer) variations in river sediment geochemistry dominate over local (meters to hundreds of meters) heterogeneity (Figure 2). Whilst processes such as hydrodynamic sorting and grainsize are generally agreed to affect sediment geochemistry locally, these effects appear to be subordinate to larger regional signals.

The successful model predictions indicate that river sediment geochemistry is primarily controlled by conservative mixing of heterogenous source regions. The lack of bias suggests that in-transit modification of sediments by physical and chemical weathering through abrasion and attrition is likely a secondary process, consistent with a recent study of Boron isotopes (Ercolani et al. 2019). The elements which are over/under-predicted by the model, as discussed in the Results section, could be exceptions to the general conservative behaviour. For example, the concentration of $\mathrm{Ca}$ is consistently under-predicted by the model. It is possible that cation exchange with the dissolved load could possibly account for this effect, as dissolved $\mathrm{Ca}$ is observed to adsorb onto riverine sediments (Cerling et al. 1989). We note that the study area has a relatively temperate climate and does not contain protracted periods of sediment storage in floodplains. Both these factors reduce the possibility of in-transit chemi$\mathrm{cal}$ and physical weathering. The composition of sediments in the Amazon and Ganges rivers, which do have large tropical floodplains, have been interpreted in terms of in-transit sediment modification which could indicate non-conservative behaviour (Bouchez et al. 2012; Lupker et al. 2012). Nonetheless, in the absence of protracted sediment storage, we suggest that downstream changes in sediment geochemistry should be interpreted primarily as a result of mixing of different source regions and not in terms of changing intensity of a particular climatic or geomorphic process. Whilst we consider only elemental geochemistry in this study, similar consideration could perhaps also be applied to sediment hosted isotopic proxies (e.g. Lithium isotopes, $\delta^{7} \mathrm{Li}$ ).

\subsection{Model limitations: Grain size, temporal evolution and erosional regimes}

In this study we account for the effect of sorting of sediments by simply extracting the fine grained portion of bed material. The sampling procedure was designed to follow that used to generate the G-BASE dataset. However, a drawback of this approach is that grainsize induced artefacts could have been introduced into the compositional dataset. Our approach implicitly assumes that the grainsize distribution of the sampled bed material fraction $(<150 \mu \mathrm{m})$ is the same at each sample site. As a result, variations in the distribution of grainsizes across the studied region could impart composition variability that is not captured by the model. Given that grainsize distributions are generally observed to vary in most riverine bed material, some of the geochemical variability not explained by our model is likely due to this effect. Indeed, some of this variability will contribute to the intrasite variance identified by the ANOVA (Figure 2f). More sophisticated sediment sampling procedures based on hydrodynamics would probably better resolve the larger regional signals from the grainsize induced 'noise' (e.g. Lupker et al. 2011; Baronas et al. 2020).

The nested ANOVA was used to quantify the possible role of local (tens to hundreds of meters) geochemical heterogeneity. However, we are not able, in this study, to quantify the possible magnitude of temporal changes in sediment geochemistry at each sample site. For example, localised geomorphic events such as landslides can induce temporary changes in sediment supply from particular parts of a catchment. In addition, seasonal changes in river hydrodynamics (e.g. flood events) may impart a seasonal grainsize distribution variability that would translate into geochemical changes as discussed above. A further concern is that the recent actions of humans have affected sediment dynamics in our study region. Globally, humans have accelerated soil erosion rates via deforestation and the expansion of agriculture and locally, dams and other human structures reduce sediment supply (Syvitski et al. 2007). The studied region contains both large areas of agricultural land-use and also two major dams which could introduce sediment supply distortions not accounted for by our model. The protected status of the Cairngorms National Park could reduce the magnitude of these potential anthropic effects. These temporal and anthropic fluctuations will contribute to the geochemical variability not explained by our model. We note that, cosmogenic nuclide studies suggest that the average residence time of sediment in drainage basins is likely to be of the order of hundreds to thousands of years (Repasch et al. 2020). These observations suggest that the composition of sediment in drainage basins might integrate processes operating on timescales of hundreds to thousands of years. Hence, whilst temporal and anthropic induced geochemical variability likely exists at some scale, it is 

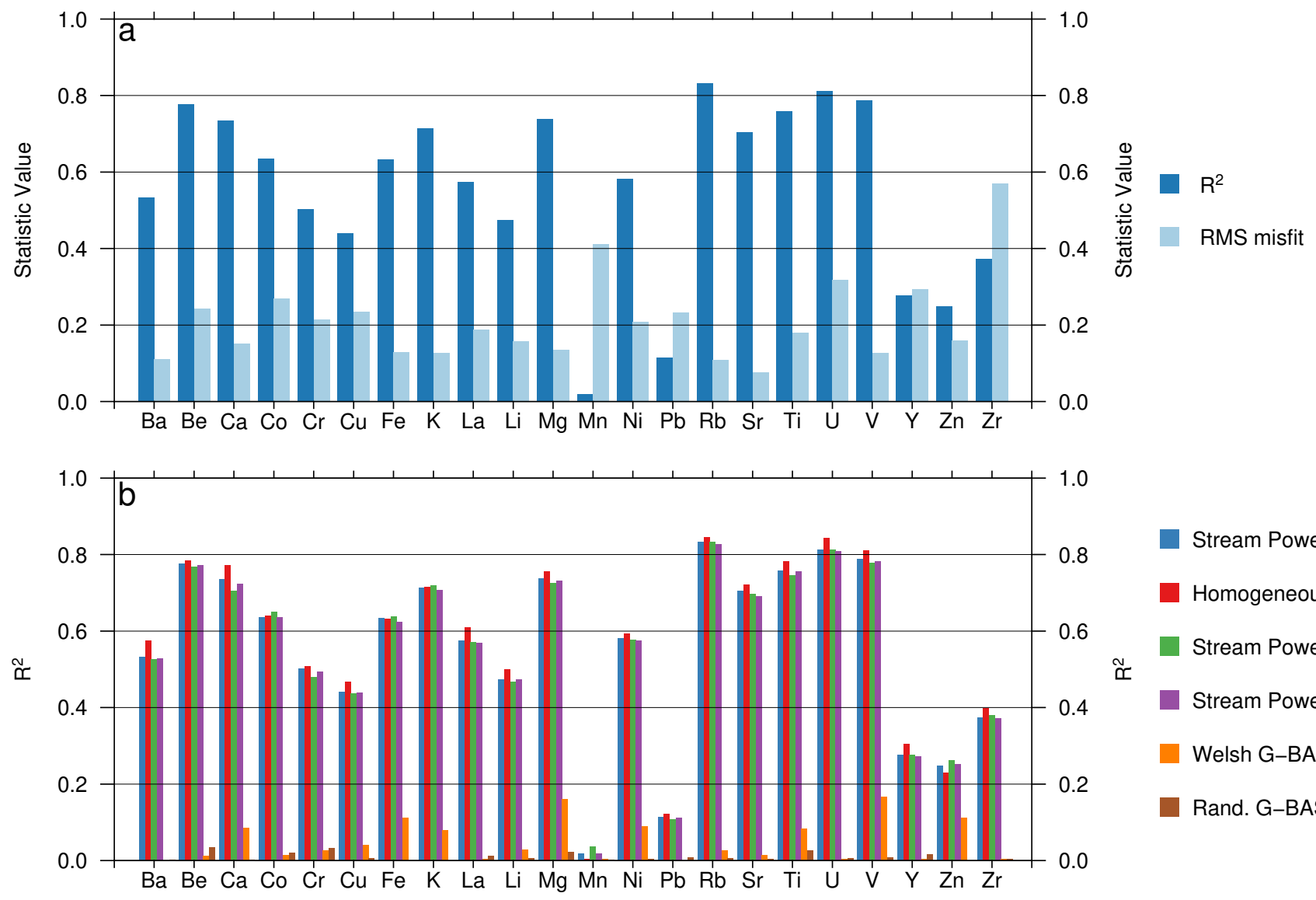

Stream Power $(n=1 ; m=0.35)$

Homogeneous incision

Stream Power $(n=2 ; m=0.35)$

ำ

Stream Power $(n=1 ; m=0.6)$

Welsh G-BASE input

Rand. G-BASE input

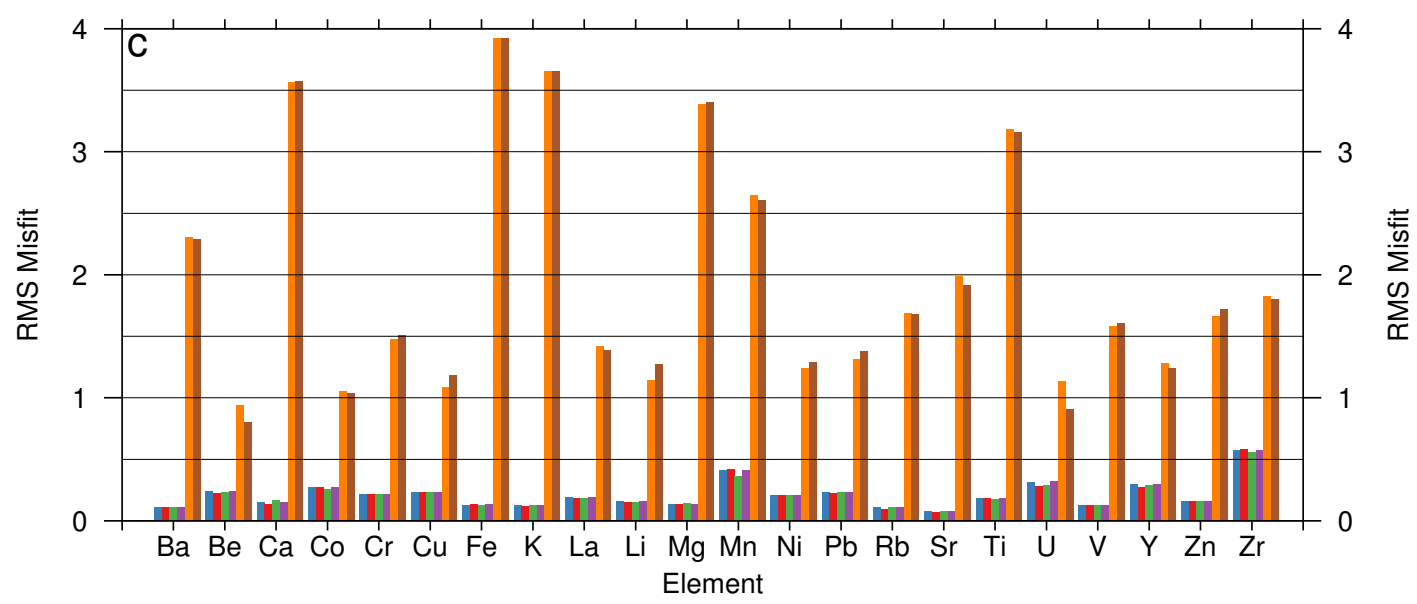

Figure 9: Evaluation of model predictions. (a) $R^{2}$ and RMS misfit between observed and predicted element concentrations for preferred Stream Power erosional $\operatorname{model}\left(n=1 ; m=0.35\right.$ ). (b) $R^{2}$ for different models and parameterisations; see key and Supporting Information for visualisation of substrate generated using Welsh G-BASE measurements and a random distribution (Figure S1). (c) RMS misfit for different models/parameterisations. 
probably subordinate to the dominant spatial trends predicted by the model and confirmed by measured compositions.

Predicted compositions are very sensitive to geochemical input, which suggests that the first-order control on river sediment geochemistry is the distribution of source rocks in their catchments The dependence on source composition is also a consequence of drainage basins containing fluvial networks that have specific topologies (i.e. geometries and spatial relationships). In contrast, we found that model predictions were insensitive to the different fluvial erosional models we tested. The linear $(n=1)$ and non-linear $(n=2)$ dependencies of incision on slope fitted the data equally well. Additionally, by changing the value of $m$ we explored sensitivity of predictions to changing basin hydrology scaling relationships. The minor differences in $R^{2}$ values suggest a weak dependency on hydrology. The most successful (highest $R^{2}$ values) erosional model we apply is homogenous erosion, i.e. a constant lowering rate across the landscape. Whilst in this location constant lowering rate generates accurate predictions, it is almost certainly not a reasonable proposition in many settings where erosion is highly variable (e.g. in active orogens) We suggest that these results are a consequence of the choice of study area, which probably had a broadly stable Holocene erosional regime and is not tectonically active. In other regions, where the erosion rates are more spatially variable (e.g. across faulted regions which generate differential uplift or with strong climatic gradients), we might expect to observe divergence between geochemical predictions from different erosional models An analogous study to our own, but in a more tectonically active area, would likely allow different erosional models to be better discriminated. We also acknowledge that more complicated erosional models could be used, such as incorporating diffusive hillslope processes. However, given that the predicted geochemistry is relatively insensitive to the particular erosional models tested, it is unclear how additional complexity would provide further insight.

\subsection{Simplifying the controls on Cairngorm river sediment composition}

A key question is what controls the spatial distribution of elemental concentrations recorded in river samples? So far we have considered each element separately, which effectively results in a 22 dimensional dataset. This high dimensionality makes interpretation challenging. To simplify interpretation, we apply principal component analysis (PCA) to the higher-order river dataset following a centred log-ratio transformation (Aitchison 1983). PCA is a widely used dimension reduction technique and is increasingly applied in sedimentary geochemical analyses (e.g. Vermeesch et al. 2015). PCA works by projecting the raw data onto a smaller number of principal components along which the variance is maximised. Hence by selecting components which contain large amounts of variance, the dimensionality of the dataset is reduced.

For the higher-order river sampling dataset, $67 \%$ of the total variance is contained on the first principal component (Figure 10d). Inspection of the loadings, i.e. the weightings of the original variables, on the first principal component suggests that it corresponds to a discrimination between rocks that might broadly defined as 'mafic' and those that might be called 'felsic' (Figure 10c). Generally, elements with positive loadings are enriched in mafic rocks (e.g. $\mathrm{Cr}, \mathrm{Mg}, \mathrm{Ni}$ ) whereas elements with negative loadings are enriched in felsic rocks (e.g. Be, K, $\mathrm{U})$. This distribution is confirmed by projecting the G-BASE data onto this component. The resulting map, shown in Figure 10a, clearly defines different geological units (Figure 1b). The felsic intrusions are highlighted in blue, relative to the more mafic rocks shown in red. We emphasise for this discussion we use 'felsic' and 'mafic' as two endmembers which exist on a geochemical continuum, not specific lithologies. Hence, the geochemical composition of sedimentary rocks (which span much of our study region) can also be projected based on their geochemistry onto this score.

This result suggests that the Cairngorms river sediments can be well described simply in terms of having either broadly mafic or broadly felsic source regions. Projecting the predicted and observed sediment compositions onto this principal component confirms this result (Figure 10b). The Spey and Dee rivers have negative PCA scores indicating a generally felsic catchment. By contrast, the Don and Deveron have positive PCA scores at the mouth, indicating a generally mafic catchment. This analysis emphasises the sensitivity of river sediment compositions to the source region geochemistry. The Don and Dee have contrasting mafic and felsic sediments but for much of their length they share a common watershed and are separated at the mouth by only $\sim 4 \mathrm{~km}$.

\subsection{Applications and further work}

Geochemical surveys such as G-BASE are widely used as baselines for environmental monitoring (e.g. Young 2016 and references therein). Higher order rivers are rarely included in sampling campaigns (for an exception see Fordyce et al. 2004). Consequently, a generic baseline for environmental monitoring of higher order river sediments is lacking. Extending baseline surveys to include sediments contained in higher-order river sediments, which, as this study shows, integrate geochemistry of their upstream region, would therefore fill a present gap in baseline applicability. Predictive models such as the one we propose, which utilise survey data as input, could be used to make baseline predictions for higher-order rivers.

We have demonstrated that sediment geochemistry can be predicted in rivers from a model that assumes conservative mixing given well constrained source region geochemistry. Here, incision is described by a Stream Power model, although all conservative mixing models tested in this study are similarly successful. This predictable behaviour of river sediments suggests that their compositions could be formally inverted to obtain maps of source-region geochemistry in drainage basins.

A further prospect implied by our results is that landscape evolution models could be parameterised using sedimentary geochemical data. In this study we have only considered a relatively small number of different parameters, changing the values of $n$ and $m$ individually. However, performing a systematic sweep of the $n$ and $m$ parameter space, to identify the parameter set that best fits the higher-order sediment geochemistry would be a novel way to parameterise a landscape evolution model. A potentially limiting scenario is the need for high-density geochemical data in the source regions. Nonetheless, many national geochemical surveys exist (e.g. in the USA; mrdata.usgs.gov/geochem) and geochemical surveying is frequently performed in areas 


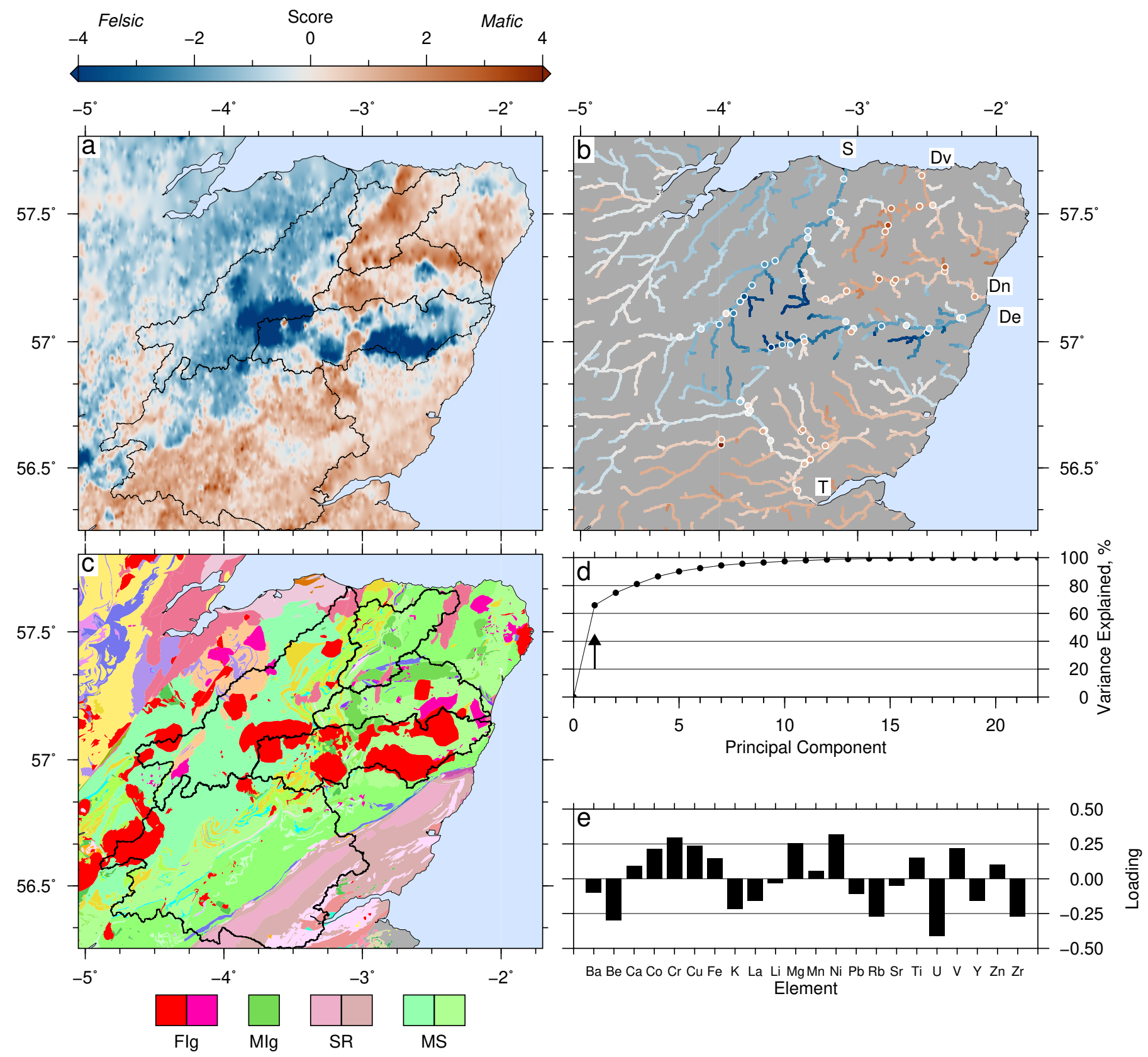

Figure 10: Principal Component Analysis (PCA) of geochemical data. PCA is applied to the higher-order river samples following centred log-ratio transformation and the loadings of the principal components were extracted. Observed compositions from the G-BASE data set and model predictions were projected onto these loadings. (a) G-BASE stream sediment data projected onto first principal component and interpolated using minimum curvature spline with tension factor of 0.25 . Note the strong relationship to bedrock geology (see panel c). (b) Observed and predicted fluvial sediment composition projected onto first principal component. The Spey and Dee carry a more felsic signature whereas the Deveron and Don are more mafic. Rivers labelled: $\mathrm{S}=$ Spey, $\mathrm{Dv}=$ Deveron, $\mathrm{Dn}=$ Don, $\mathrm{De}=$ Dee, $\mathrm{T}=$ Tay. (c) Geological map of study region reproduced from Figure $1 \mathrm{~b}$. Key lithologies: Flg = Ordovician to Devonian felsic igneous intrusions; Mlg = Ordovician to Silurian mafic igneous intrusions; $\mathrm{SR}=$ Sedimentary rocks, mostly Devonian sandstones; MS = Metasedimentary rocks, mostly Neoproterozoic psammites. See mapapps.bgs.ac.uk/geologyofbritain/home.html for full geologic key; reproduced with the permission of the British Geological Survey UKRI, all rights reserved. (d) Variance contained on each principal component. Arrow indicates first principal component (displayed here; PC1), which contains 68\% (i.e., the majority) of the total variance within the observed geochemical dataset. (e) Loadings on PC1 indicate the geological processes underlying the principal component. Elements with positive loadings are typically associated with mafic igneous rocks whereas negative loadings are associated with felsic rocks. 
of potential mineral resources by the mining industry. There is therefore likely a large amount of legacy geochemical data that could be utilised, in combination with specifically gathered higher-order river data, to parameterise erosional models.

More generally, our approach can be tested and applied anywhere with suitable upstream geochemical data. Whilst G-BASE is, as far as we aware, the only national geochemical survey of such a high-density, the approach we propose could plausibly be adapted to surveys with lower density sampling. The specific sampling density required will, however, be dependent on the expected geochemical variability of the studied region. Where geochemical data is not available, it could be possible to parameterise geological maps, which are more widely available, in terms of geochemical compositions. Finally, recent advances have been made in using machine learning to predict substrate chemistry from a range of more widely available remote sensing and potential field data (e.g. Kirkwood et al. 2016a; Wilford et al. 2016).

\section{Conclusions}

We develop a model to predict the geochemical composition of higher order river sediments using erosional models and maps of source region geochemistry. This scheme is tested in a case study of the Cairngorms, UK. Statistical analysis of point measurements gathered across the region show that regional geochemical variability dominates over local heterogeneity. The model is successful in explaining the majority of the observed variance for 15 of our 22 studied elements. For our chosen region, the predicted sediment geochemistry is insensitive to the erosional parameters chosen, which is likely due to the homogeneous climatic and tectonic regime of our study area. By contrast, we find that sediment geochemistry is highly sensitive to the spatial distribution of the source region geochemistry. In the Cairngorms river sediment composition is primarily set by conservative mixing of heterogeneous source regions, which can be predicted using simple erosional models. In our study region, river sediment geochemistry can be additionally described simply in terms of mixtures of source region geochemistry which exist on a continuum between mafic and felsic endmembers Our predictive scheme indicates that quantitative modelling, and inversion, of fluvial geochemical signals is a promising avenue of further research.

\section{Data And Code Availability}

Code and data is available at github.com/AlexLipp/ predict-river-chem and archived at the point of submission at doi.org/10.5281/zenodo.3839551.

\section{AcKNOWLEDGEMENTS}

The authors are extremely grateful to the BGS staff for providing access to data, equipment and expertise on geochemical surveying as well as support in sample preparation and analysis. The authors also thank the kind people of Scotland who let us sample on their property. This research was supported by CASP. AGL is funded by the Natural Environment Research Council Grantham Institute SSCP DTP [grant number NE/L002515/1] and performed labwork at BGS under a BUFI studentship.

\section{REFERENCES}

Aitchison, J. (1983). "Principal component analysis of compositional data". Biometrika 70.1, pp. 57-65. Dor: 10.1093/ biomet/70.1.57.

Ballantyne, C. K. (2008). "After the Ice: Holocene Geomorphic Activity in the Scottish Highlands". Scottish Geographical Journal 124.1, pp. 8-52. DOI: 10 . 1080 / 14702540802300167.

Barnes, R., C. Lehman, and D. Mulla (2014). "Priority-flood: An optimal depression-filling and watershed-labeling algorithm for digital elevation models". Computers $\mathcal{F}$ Geosciences 62, pp. 117-127. Dor: 10.1016/j . cageo.2013.04.024.

Baronas, J. J., E. I. Stevenson, C. R. Hackney, S. E. Darby, M. J. Bickle, R. G. Hilton, C. S. Larkin, D. R. Parsons, A. M. Khaing, and E. T. Tipper (2020). "Integrating Suspended Sediment Flux in Large Alluvial River Channels: Application of a Synoptic Rouse-Based Model to the Irrawaddy and Salween Rivers". Journal of Geophysical Research: Earth Surface 125.9, e2020JF005554. DoI: 10.1029/2020JF005554.

Blanckenburg, F. von (2005). "The control mechanisms of erosion and weathering at basin scale from cosmogenic nuclides in river sediment". Earth and Planetary Science Letters 237.3, pp. 462-479. Dor: 10.1016/j .epsl.2005.06.030.

Blanckenburg, F. von, J. Bouchez, and H. Wittmann (2012). "Earth surface erosion and weathering from the 10Be (meteoric)/9Be ratio". Earth and Planetary Science Letters 351352, pp. 295-305. DoI: 10.1016/j .epsl.2012.07.022.

Bouchez, J., J. Gaillardet, C. France-Lanord, L. Maurice, and P. Dutra-Maia (2011). "Grain size control of river suspended sediment geochemistry: Clues from Amazon River depth profiles". Geochemistry, Geophysics, Geosystems 12.3. DOI: 10.1029/2010GC003380.

Bouchez, J., J. Gaillardet, M. Lupker, P. Louvat, C. FranceLanord, L. Maurice, E. Armijos, and J.-S. Moquet (2012). "Floodplains of large rivers: Weathering reactors or simple silos?" Chemical Geology 332-333, pp. 166-184. DoI: 10 1016/j . chemgeo.2012.09.032.

Braun, J. and S. D. Willett (2013). "A very efficient O(n), implicit and parallel method to solve the stream power equation governing fluvial incision and landscape evolution". Geomorphology 180-181, pp. 170-179. DoI: 10.1016/j.geomorph 2012.10.008.

Caritat, P. d. and M. Cooper (2016). "A continental-scale geochemical atlas for resource exploration and environmental management: the National Geochemical Survey of Australia". Geochemistry: Exploration, Environment, Analysis 16.1, pp. 3-13. DoI: 10.1144/geochem2014-322.

Cerling, T. E., B. L. Pederson, and K. L. V. Damm (1989). "Sodium-calcium ion exchange in the weathering of shales: Implications for global weathering budgets". Geology 17.6, pp. 552-554. Dor: 10 . 1130/0091-7613 (1989) 017<0552 : SCIEIT>2.3. CO; 2 .

Ercolani, C., D. Lemarchand, and A. Dosseto (2019). "Insights on catchment-wide weathering regimes from boron isotopes in riverine material". Geochimica et Cosmochimica Acta. Dor: 10.1016/j.gca.2019.07.002.

Everett, P., A. Donald, A. Ferreira, F. Fordyce, C. Gowing, R. Lawley, T. Lister, B. Palumbo-Roe, and British Geological Survey (2019). Stream sediment geochemical atlas of the 
United Kingdom: British Geological Survey report OR/18/048. British Geological Survey.

Farr, T. G., P. A. Rosen, E. Caro, R. Crippen, R. Duren, S. Hensley, M. Kobrick, M. Paller, E. Rodriguez, L. Roth, D. Seal, S. Shaffer, J. Shimada, J. Umland, M. Werner, M. Oskin, D. Burbank, and D. Alsdorf (2007). "The Shuttle Radar Topography Mission". Reviews of Geophysics 45.2. Dor: 10.1029/ 2005RG000183.

Fernandes, V. M., G. G. Roberts, N. White, and A. C. Whittaker (2019). "Continental-Scale Landscape Evolution: A History of North American Topography". Journal of Geophysical Research: Earth Surface 124.11, pp. 2689-2722. DoI: 10 . 1029/2018JF004979.

Fordyce, F. M., B. E. O Dochartaigh, T. R. Lister, R. Cooper, A. Kim, I. Harrison, C. Vane, and S. E. Brown (2004). Clyde tributaries : report of urban stream sediment and surface water geochemistry for Glasgow. Internal Report CR/04/037N. Nottingham, UK: British Geological Survey. Dor: http://nora. nerc.ac.uk/id/eprint/18996/10/Erratum.pdf.

Gaillardet, J., B. Dupré, and C. J. Allègre (1999). "Geochemistry of large river suspended sediments: silicate weathering or recycling tracer?" Geochimica et Cosmochimica Acta 63.23, pp. 4037-4051. Dor: 10.1016/S0016-7037 (99) 00307-5.

Garrett, R., C. Reimann, D. Smith, and X. Xie (2008). "From geochemical prospecting to international geochemical mapping: a historical overview". Geochemistry: Exploration, Environment, Analysis 8.3-4, pp. 205-217. Dor: 10.1144/14677873/08- 174 .

Garrett, R. G. (1969). "The determination of sampling and analytical errors in exploration geochemistry". Economic Geology 64.5, pp. 568-569. Dor: 10.2113/gsecongeo.64.5. 568.

Garzanti, E., P. Dinis, P. Vermeesch, S. Andò, A. Hahn, J. Huvi, M. Limonta, M. Padoan, A. Resentini, M. Rittner, and G. Vezzoli (2018). "Dynamic uplift, recycling, and climate control on the petrology of passive-margin sand (Angola)". Sedimentary Geology. Analysis of sediment properties 375, pp. 86104. Dor: $10.1016 / \mathrm{j}$. sedgeo. 2017.12.009.

Hobley, D. E. J., J. M. Adams, S. S. Nudurupati, E. W. H. Hutton, N. M. Gasparini, E. Istanbulluoglu, and G. E. Tucker (2017). "Creative computing with Landlab: an open-source toolkit for building, coupling, and exploring two-dimensional numerical models of Earth-surface dynamics". Earth Surface Dynamics 5.1, pp. 21-46. Dor: https ://doi .org/10.5194/esurf 5-21- 2017.

Holbrook, J. and H. Wanas (2014). "A Fulcrum Approach To Assessing Source-To-Sink Mass Balance Using Channel Paleohydrologic Paramaters Derivable From Common Fluvial Data Sets With An Example From the Cretaceous of Egypt". Journal of Sedimentary Research 84.5, pp. 349-372. Dor: 10.2110/jsr.2014.29.

Howard, A. D. and G. Kerby (1983). "Channel changes in badlands". GSA Bulletin 94.6, pp. 739-752. Dor: 10.1130/00167606 (1983) 94<739: CCIB>2 . 0.CO; 2.

Jager, A. L. d. and J. V. Vogt (2010). "Development and demonstration of a structured hydrological feature coding system for Europe". Hydrological Sciences Journal 55.5, pp. 661-675. Dor: 10.1080/02626667.2010.490786.

Johnson, C. C., N. Breward, E. L. Ander, and L. Ault (2005). "G-BASE: baseline geochemical mapping of Great Britain and Northern Ireland". Geochemistry: Exploration, Environment,
Analysis 5.4, pp. 347-357. Dor: 10.1144/1467-7873/05070.

Johnson, C. C., E. L. Ander, T. R. Lister, and D. M. A. Flight (2018a). "Chapter 5 - Data Conditioning of Environmental Geochemical Data: Quality Control Procedures Used in the British Geological Survey's Regional Geochemical Mapping Project". In: Environmental Geochemistry (Second Edition). Ed. by B. De Vivo, H. E. Belkin, and A. Lima. 2nd ed. Elsevier, pp. 79-101. Dor: 10 . 1016/B978- 0-444-63763$5.00006-9$.

Johnson, C. C., D. M. A. Flight, E. L. Ander, T. R. Lister, N. Breward, F. M. Fordyce, S. E. Nice, and K. V. Knights (2018b). "Chapter 4 - The Collection of Drainage Samples for Environmental Analyses From Active Stream Channels". In: Environmental Geochemistry (Second Edition). Ed. by B. De Vivo, H. E. Belkin, and A. Lima. 2nd ed. Elsevier, pp. 47-77. Dor: 10.1016/B978-0-444-63763-5.00005-7.

Karlstrom, K. E., R. Crow, L. J. Crossey, D. Coblentz, and J. W. V. Wijk (2008). "Model for tectonically driven incision of the younger than $6 \mathrm{Ma}$ Grand Canyon". Geology 36.11, pp. 835-838. Dor: 10.1130/G25032A.1.

Kim, S.-M., Y. Choi, H. Yi, and H.-D. Park (2017). "Geostatistical prediction of heavy metal concentrations in stream sediments considering the stream networks". Environmental Earth Sciences 76.2, p. 72. Dor: 10 . 1007 /s12665 - 017 6394-2.

Kirkwood, C., M. Cave, D. Beamish, S. Grebby, and A. Ferreira (2016a). "A machine learning approach to geochemical mapping". Journal of Geochemical Exploration 167, pp. 49-61. Dor: $10.1016 / j$.gexplo.2016.05.003.

Kirkwood, C., M. Cooper, A. Ferreira, and D. Beamish (2020). "Unmixing and mapping components of Northern Ireland's geochemical composition using FastICA and random forests".

Kirkwood, C., P. Everett, A. Ferreira, and B. Lister (2016b). "Stream sediment geochemistry as a tool for enhancing geological understanding: An overview of new data from south west England". Journal of Geochemical Exploration 163, pp. 28-40. DoI: 10.1016/j . gexplo.2016.01.010.

Kottek, M., J. Grieser, C. Beck, B. Rudolf, and F. Rubel (2006). "World Map of the Köppen-Geiger climate classification updated". Meteorologische Zeitschrift 15.3, pp. 259-263. DoI: 10.1127/0941-2948/2006/0130.

Lupker, M., C. France-Lanord, V. Galy, J. Lavé, J. Gaillardet, A. P. Gajurel, C. Guilmette, M. Rahman, S. K. Singh, and R. Sinha (2012). "Predominant floodplain over mountain weathering of Himalayan sediments (Ganga basin)". Geochimica et Cosmochimica Acta 84, pp. 410-432. DoI: 10.1016/j . gca. 2012.02 .001$.

Lupker, M., C. France-Lanord, and B. Lartiges (2016). "Impact of sediment-seawater cation exchange on Himalayan chemical weathering fluxes". Earth Surface Dynamics Discussions, pp. 1-15. Dor: 10.5194/esurf-2016-26.

Lupker, M., C. France-Lanord, J. Lavé, J. Bouchez, V. Galy, F. Métivier, J. Gaillardet, B. Lartiges, and J.-L. Mugnier (2011). "A Rouse-based method to integrate the chemical composition of river sediments: Application to the Ganga basin". Journal of Geophysical Research: Earth Surface 116.F4. Dor: 10 . 1029/2010JF001947.

Paul, J. D., G. G. Roberts, and N. White (2014). "The African landscape through space and time". Tectonics 33.6, pp. 898 935. Dor: $10.1002 / 2013 T C 003479$. 
Pritchard, D., G. G. Roberts, N. J. White, and C. N. Richardson (2009). "Uplift histories from river profiles". Geophysical Research Letters 36.24. DoI: 10.1029/2009GL040928.

Quye-Sawyer, J., A. C. Whittaker, and G. G. Roberts (2020). "Calibrating fluvial erosion laws and quantifying river response to faulting in Sardinia, Italy". Geomorphology 370, p. 107388. DoI: 10.1016/j .geomorph. 2020.107388.

Repasch, M., H. Wittmann, J. S. Scheingross, D. Sachse, R. Szupiany, O. Orfeo, M. Fuchs, and N. Hovius (2020). "Sediment Transit Time and Floodplain Storage Dynamics in Alluvial Rivers Revealed by Meteoric 10Be". Journal of Geophysical Research: Earth Surface 125.7, e2019JF005419. DoI: 10.1029/2019JF005419.

Riebe, C. S., J. W. Kirchner, and R. C. Finkel (2003). "Long-term rates of chemical weathering and physical erosion from cosmogenic nuclides and geochemical mass balance". Geochimica et Cosmochimica Acta 67.22, pp. 4411-4427. DoI: 10 1016/S0016-7037 (03)00382-X.

Romans, B. W., S. Castelltort, J. A. Covault, A. Fildani, and J. P. Walsh (2016). "Environmental signal propagation in sedimentary systems across timescales". Earth-Science Reviews. Source-to-Sink Systems: Sediment \& Solute Transfer on the Earth Surface 153, pp. 7-29. DoI: 10.1016/j . earscirev . 2015.07.012.

Rosenbloom, N. A. and R. S. Anderson (1994). "Hillslope and channel evolution in a marine terraced landscape, Santa Cruz, California". Journal of Geophysical Research: Solid Earth 99.B7, pp. 14013-14029. Dor: 10.1029/94JB00048.

Royden, L. and J. T. Perron (2013). "Solutions of the stream power equation and application to the evolution of river longitudinal profiles". Journal of Geophysical Research: Earth Surface 118.2, pp. 497-518. DoI: 10.1002/jgrf . 20031.

Rudge, J. F., G. G. Roberts, N. J. White, and C. N. Richardson (2015). "Uplift histories of Africa and Australia from linear inverse modeling of drainage inventories". Journal of Geophysical Research: Earth Surface 120.5, pp. 894-914. DoI: 10.1002/2014JF003297.

Salles, T. (2019). "eSCAPE: Regional to Global Scale Landscape Evolution Model v2.0”. Geoscientific Model Development Discussions, pp. 1-28. Dor: https : // doi . org/10 . 5194/gmd-2019-126.

Salles, T., X. Ding, and G. Brocard (2018). "pyBadlands: A framework to simulate sediment transport, landscape dynamics and basin stratigraphic evolution through space and time". PLOS ONE 13.4, e0195557. Dor: 10.1371/journal .pone. 0195557.

Sharman, G. R., Z. Sylvester, and J. A. Covault (2019). “Conversion of tectonic and climatic forcings into records of sediment supply and provenance". Scientific Reports 9.1, p. 4115. Dor: 10.1038/s41598-019-39754-6.

Smith, D. B., S. M. Smith, and J. D. Horton (2013). "History and evaluation of national-scale geochemical data sets for the United States". Geoscience Frontiers 4.2, pp. 167-183. Dor: 10.1016/j.gsf .2012.07.002.

Smith, W. H. F. and P. Wessel (1990). "Gridding with continuous curvature splines in tension”. Geophysics 55.3, pp. 293-305. DOI: $10.1190 / 1.1442837$.

Stephenson, S. N., G. G. Roberts, M. J. Hoggard, and A. C. Whittaker (2014). "A Cenozoic uplift history of Mexico and its surroundings from longitudinal river profiles". Geochem- istry, Geophysics, Geosystems 15.12, pp. 4734-4758. DoI: 10.1002/2014GC005425.

Stock, J. D. and D. R. Montgomery (1999). "Geologic constraints on bedrock river incision using the stream power law". Journal of Geophysical Research: Solid Earth 104.B3, pp. 4983-4993. Dor: 10.1029/98JB02139.

Stucky de Quay, G., G. G. Roberts, D. H. Rood, and V. M. Fernandes (2019). "Holocene uplift and rapid fluvial erosion of Iceland: A record of post-glacial landscape evolution". Earth and Planetary Science Letters 505, pp. 118-130. Dor: 10.1016/j.epsl.2018.10.026.

Syvitski, J. P. M. and J. D. Milliman (2007). “Geology, Geography, and Humans Battle for Dominance over the Delivery of Fluvial Sediment to the Coastal Ocean". The Journal of Geology 115.1, pp. 1-19. Dor: 10.1086/509246.

Tucker, G. E. and K. X. Whipple (2002). "Topographic outcomes predicted by stream erosion models: Sensitivity analysis and intermodel comparison". Journal of Geophysical Research: Solid Earth 107.B9, ETG 1-1-ETG 1-16. DoI: 10 . 1029/ 2001 JB000162.

Van Rossum, G. and F. L. Drake (2009). Python 3 Reference Manual. Scotts Valley, CA: CreateSpace.

Vermeesch, P. and E. Garzanti (2015). "Making geological sense of 'Big Data' in sedimentary provenance analysis". Chemical Geology 409, pp. 20-27. DoI: 10.1016/ j . chemgeo . 2015. 05.004.

Weltje, G. J. (2012). "Quantitative models of sediment generation and provenance: State of the art and future developments". Sedimentary Geology. Actualistic Models of Sediment Generation 280, pp. 4-20. DoI: 10.1016/j . sedgeo.2012.03. 010.

Wessel, P., W. H. F. Smith, R. Scharroo, J. Luis, and F. Wobbe (2013). "Generic Mapping Tools: Improved Version Released". Eos, Transactions American Geophysical Union 94.45, pp. 409-410. Dor: 10.1002/2013E0450001.

Whipple, K. X. and G. E. Tucker (1999). "Dynamics of the stream-power river incision model: Implications for height limits of mountain ranges, landscape response timescales, and research needs". Journal of Geophysical Research: Solid Earth 104.B8, pp. 17661-17674. Dor: 10 . 1029 / 1999 JB900120.

- (2002). "Implications of sediment-flux-dependent river incision models for landscape evolution". Journal of Geophysical Research: Solid Earth 107.B2, ETG 3-1-ETG 3-20. DoI: 10.1029/2000 JB000044.

Wilford, J., P. de Caritat, and E. Bui (2016). "Predictive geochemical mapping using environmental correlation". Applied Geochemistry 66, pp. 275-288. Dor: 10.1016/j . apgeochem. 2015.08 .012$.

"The Tellus geochemical surveys, results and applications" (2016). In: Unearthed: Impacts of the Tellus surveys of the north of Ireland. Ed. by M. Young. Royal Irish Academy. Dor: 10.2307/j.ctt1g69w6r. 


\section{SUPPORTING INFORMATION}

The supporting information contains supplementary figures that show the results of tests in which input to the predictive geochemical model was changed and an exploration of model predictions. A time-lapse video that shows the higher-order river sediment sampling procedure is also included as additional supplementary material.

Figure $\mathrm{S} 1$ shows predicted concentrations of $\mathrm{Mg}$ downstream if substrate, which is input to the model, is changed. In the first test substrate is substituted for a section of the G-BASE dataset taken from elsewhere in the UK (arbitrarily, Wales/Herefordshire). In the second test the G-BASE measurements from the study region are randomised before interpolation and insertion into the model. As Figures S1b and S1d show, neither approach generates accurate predictions of downstream chemistry (see coloured circles and inset panels). In contrast, using the actual geochemistry of the Cairngorms (extracted the G-BASE dataset) generates accurate predictions (see main manuscript). These results emphasise the sensitivity of downstream geochemistry to the specific distribution of upstream geochemistry.

Figure S2 shows the global root-mean-squared (RMS) misfit for all elements in this study. RMS misfit, $H$, is calculated such that

$$
H=\left[\frac{1}{N} \sum_{i=1}^{N}\left(\log _{10} C_{o}^{i}-\log _{10} C_{c}^{i}\right)^{2}\right]^{1 / 2}
$$

where $N$ is the number of measured elemental concentrations for each sample, $C_{o}$ and $C_{c}$ are observed and calculated concentrations of each element $(i)$.

Figures S3-S24 show the spatial misfit for each element, $\log _{10} C_{o}^{i}-\log _{10} C_{c}^{i}$. These are not included in this document, and can be found in the Supporting Information repository and at github.com/AlexLipp/predict-river-chem.

Supporting video $\mathrm{S} 1$, is a timelapse demonstrating the higher-order river sediment sampling procedure used in this study. This video can be found at github.com/AlexLipp/ predict-river-chem. 

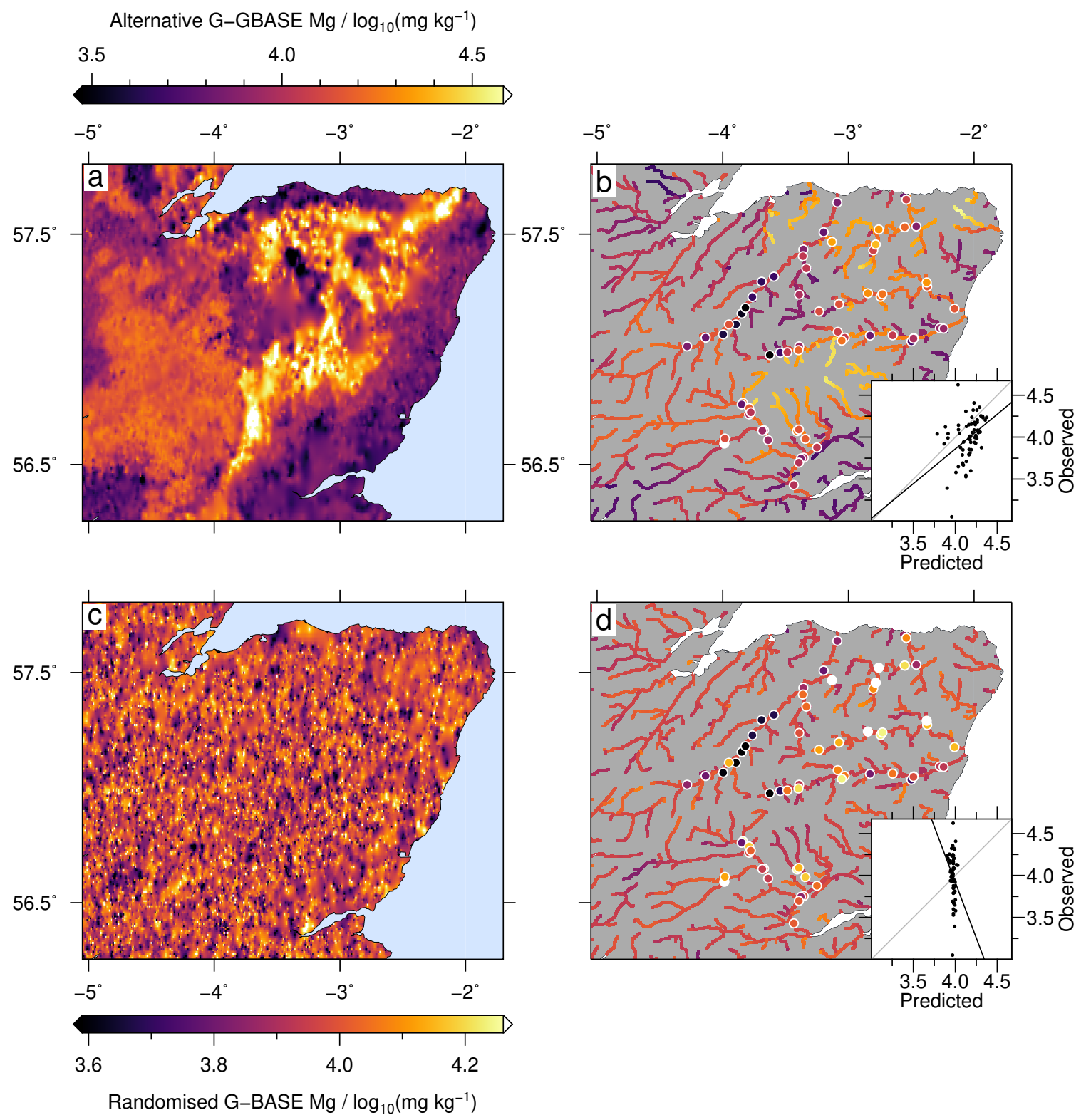

Supplementary Figure 1: Results for Mg when different geochemical inputs are made. a) Interpolated G-BASE grid taken from elsewhere in UK, here Wales/Herefordshire. b) Results of using this input compared to observed data. c) Interpolated grid created when randomising the Cairngorms GBASE samples. d) Results of using this input compared to observed data. 


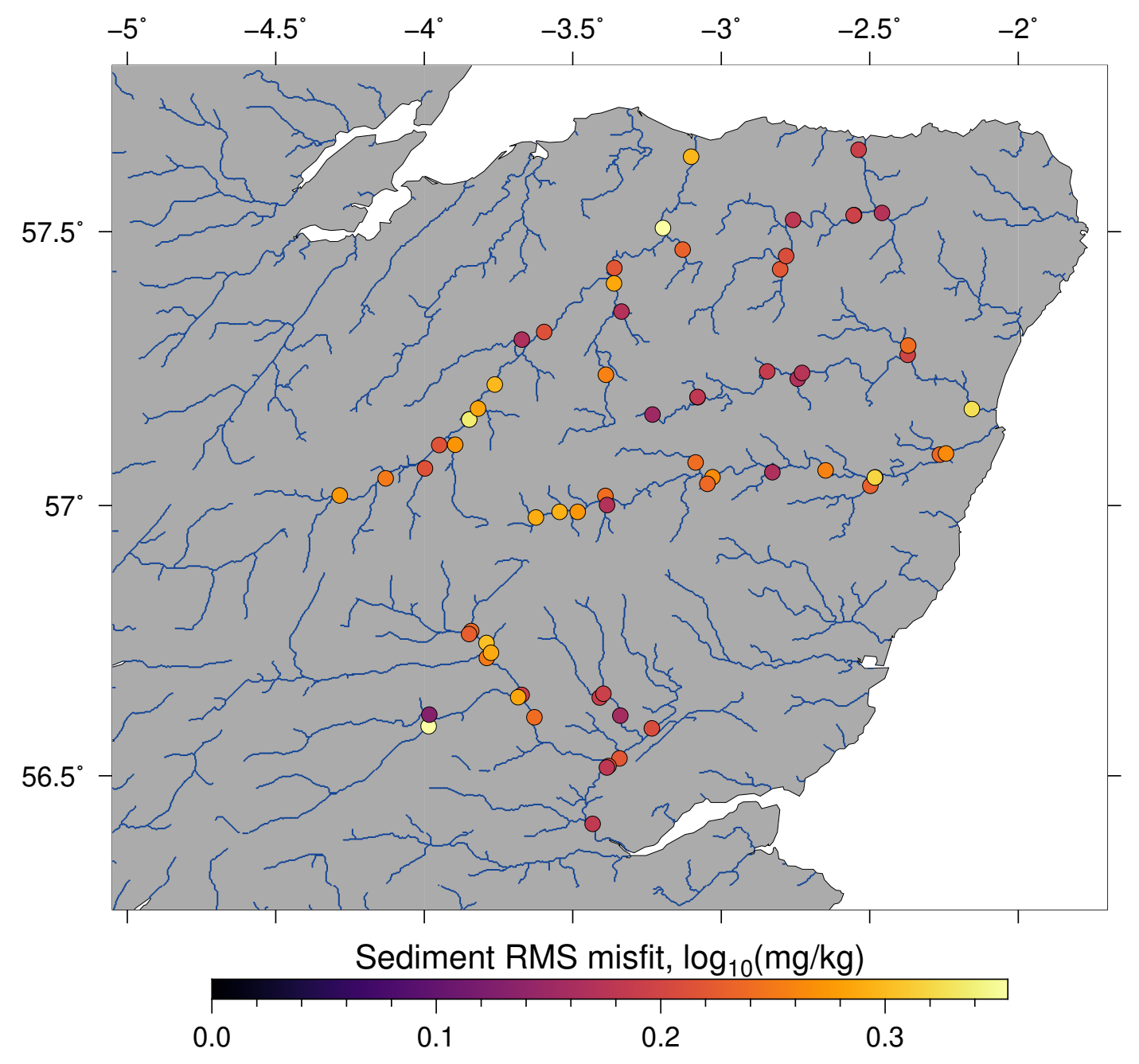

Supplementary Figure 2: Global RMS misfit for all samples in this study. 